\title{
AKAP79 enables calcineurin to directly suppress protein kinase $\mathrm{A}$ activity
}

\section{Timothy W Church1, Parul Tewatia ${ }^{2,3}$, Saad Hannan1, João Antunes ${ }^{2}$, Olivia Eriksson ${ }^{2}$, Trevor G Smart ${ }^{1}$, Jeanette Hellgren Kotaleski ${ }^{2,3}$, Matthew G Gold ${ }^{1 *}$}

\author{
${ }^{1}$ Department of Neuroscience, Physiology \& Pharmacology, University College \\ London, London, United Kingdom; ${ }^{2}$ Science for Life Laboratory, School of Electrical \\ Engineering and Computer Science, KTH Royal Institute of Technology, Stockholm, \\ Sweden; ${ }^{3}$ Department of Neuroscience, Karolinska Institute, Stockholm, Sweden
}

*For correspondence: m.gold@ucl.ac.uk

Competing interest: The authors declare that no competing interests exist.

Funding: See page 23

Received: 07 March 2021 Preprinted: 15 March 2021 Accepted: 04 October 2021 Published: 06 October 2021

Reviewing Editor: Amy Andreotti, lowa State University, United States

(c) Copyright Church et al. This article is distributed under the terms of the Creative Commons Attribution License, which permits unrestricted use and redistribution provided that the original author and source are credited.

\section{Introduction}

Cyclic adenosine monophosphate (cAMP) and $\mathrm{Ca}^{2+}$ are ancient second messengers that are fundamental to the regulation of many dynamic cellular processes including synaptic plasticity (Huang et al., 1994), heart contraction (Bers et al., 2019), and glycogen metabolism (Roach et al., 2012). Crosstalk between the two second messengers is a common feature of cellular signaling. For example, cAMP can enhance cytosolic $\mathrm{Ca}^{2+}$ entry by triggering phosphorylation of key ion channels (Qian et al., 2017; Schmitt et al., 2003) by its major intracellular receptor cAMP-dependent protein kinase, also known as Protein Kinase A (PKA). Similarly, $\mathrm{Ca}^{2+}$ can regulate cAMP levels by altering activities of both phosphodiesterases (Baillie et al., 2019) and adenylyl cyclases (Qi et al., 2019). At the receptor level, a common signaling motif is the opposition of PKA and the highly abundant $\mathrm{Ca}^{2+}$-sensitive phosphatase calcineurin $(\mathrm{CN})$, with $\mathrm{CN}$ triggering cellular changes by removing phosphate from substrates primed by PKA. Notable examples of this motif are the regulation of postsynaptic substrates including AMPA-type glutamate receptors in the induction of long-term depression (LTD) of synaptic strength (Bear, 2003), and control of NFAT nuclear localization in immune responses (Hogan, 2017). According to current consensus, in these cases $\mathrm{CN}$ dephosphorylates substrates without any requirement for directly altering PKA activity (Dittmer et al., 2014; Lu et al., 2011; Tunquist et al., 2008; Weisenhaus et al., 2010; Zhang and Shapiro, 2016). This implies that energetically costly futile cycles of phosphate addition and removal by PKA and CN must persist to maintain dephosphorylated substrate. It would be more logical for PKA activity to be switched off when $\mathrm{CN}$ is activated during substrate dephosphorylation. Uncovering the mechanism to achieve this is the focus of this study. 


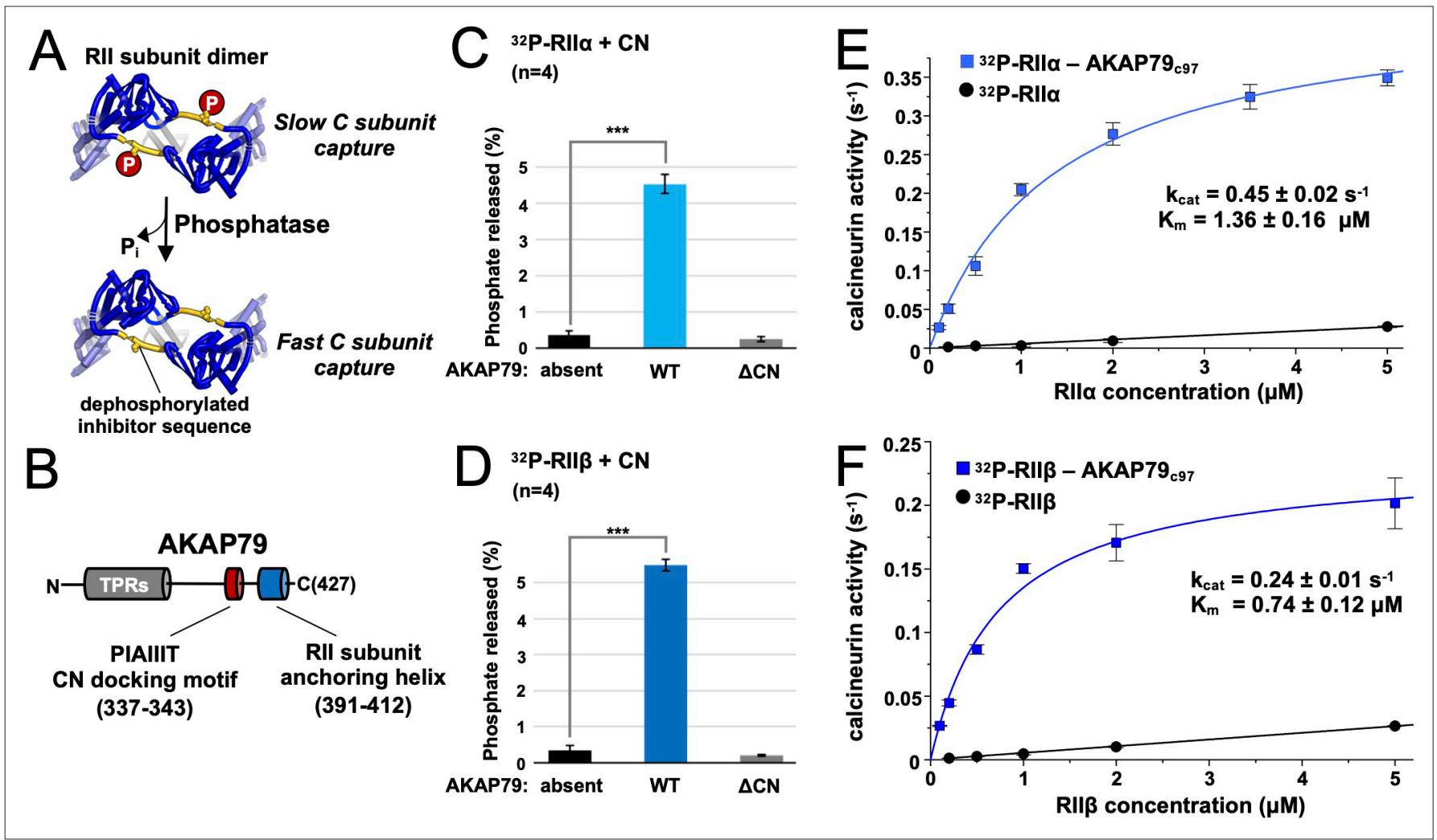

Figure 1. Effect of AKAP79 on pRII dephosphorylation by CN. (A) Dephosphorylation of the inhibitor sequence (IS, yellow) of RIl subunits enables faster PKA C subunit capture. (B) AKAP79 contains anchoring sites for CN (red) and PKA RIl subunits (blue) in its C-terminal region. Other macromolecular interactions are mediated through elements within its tandem polybasic regions (TPRs, gray). (C) CN-catalyzed phosphate release from pRll $\alpha$ subunits with either no AKAP79, WT AKAP79 (light blue), or AKAP79 lacking the PIAIIIT anchoring motif (' $\triangle C N^{\prime}$ ). (D) CN-catalyzed phosphate release from pRII $\beta$ subunits with either no AKAP79, WT AKAP79 (dark blue), or AKAP79 $\triangle \mathrm{CN}$. (E) The relationship between CN activity toward pRIl $\alpha$ subunits and pRIl $\alpha$ concentration with pRIl $\alpha$ subunits included either alone (black circles) or in complex with AKAP79 ${ }_{c 97}$ (light blue squares). (F) The relationship between CN activity towards pRII $\beta$ subunits and pRII $\beta$ concentration with pRII $\beta$ subunits included either alone (black circles) or in complex with AKAP79 997 (dark blue squares). For panels $E$ and $F$, activities at each concentration were measured in triplicate. Statistical comparisons were performed using two-tailed unpaired Student $t$-tests. ${ }^{\star \star \star} p<0.001$.

The online version of this article includes the following figure supplement(s) for figure 1:

Source data 1. Radioactive phosphatase assays.

Figure supplement 1. Purified proteins.

Figure supplement 2. pRII phosphorylation by $\mathrm{CN}$ at supra-physiological concentrations.

Figure supplement 2-source data 1. Phosphatase assays without AKAP79.

Figure supplement 3. Effect of AKAP79c97 variants on pNPP and pRII phosphopeptide dephosphorylation.

Figure supplement 3-source data 1. Colorimetric phosphatase assays.

Recent years have seen renewed interest in mechanisms for regulating the release and re-capture of PKA catalytic subunits (Bock et al., 2020; Gold, 2019; Zhang et al., 2020), including new data that hint at how CN might directly suppress PKA activity. PKA is comprised of regulatory subunit dimers that bind and sequester PKA catalytic (C) subunits in an inhibited state (Taylor et al., 2019). PKA regulatory subunits are classified into type I subunits (RI $\alpha$ and $R I \beta)$ that are predominantly cytosolic, and type II subunits (RII $\alpha$ and RIIß) that co-sediment with membranes (Gold, 2019). The regulatory subunit inhibitor sequence (IS) is phosphorylated upon association with C subunits for RII but not RI subunits, which bear alanine in place of serine in the phospho-acceptor site (S98 in RIl $\alpha$ ). Quantitative immunoblotting and mass spectrometry (MS) have recently shown that PKA regulatory subunits - and particularly RIl subunits - greatly outnumber PKA C subunits (Aye et al., 2010; Walker-Gray et al., 2017) throughout the body. In addition, Zhang et al., 2015 have extended earlier observations (RangelAldao and Rosen, 1976) to quantify differences in the rate of $C$ subunit binding to RII subunits either 
phosphorylated (pRII) or dephosphorylated at the IS. Remarkably, the $\mathrm{k}_{\text {on }}$ rate for $\mathrm{C}$ subunit association is 50 times faster for dephosphorylated RII than pRII (Zhang et al., 2015; Figure 1A). In theory, rapid dephosphorylation of RII subunits by CN could directly suppress PKA activity by increasing the rate of C subunit capture thereby reducing the proportion of $C$ subunits that are dissociated (Buxbaum and Dudai, 1989; Isensee et al., 2018; Ogreid and Døskeland, 1981; Stemmer and Klee, 1994; Zhang et al., 2015; Zhang et al., 2012). While recent observations concerning PKA subunit stoichiometry and $\mathrm{pRII/RII} \mathrm{binding} \mathrm{kinetics} \mathrm{support} \mathrm{this} \mathrm{notion,} \mathrm{isolated} \mathrm{pRII} \mathrm{is} \mathrm{a} \mathrm{low-affinity} \mathrm{substrate} \mathrm{for} \mathrm{CN} \mathrm{with}$ a half-maximal substrate concentration $\left(\mathrm{K}_{\mathrm{m}}\right)$ above $20 \mu \mathrm{M}$ (Blumenthal et al., 1986; Perrino et al., 1992; Stemmer and Klee, 1994). Therefore, pRII dephosphorylation by CN would not be expected to occur to a meaningful degree at physiological concentrations in the absence of an additional factor.

Anchoring proteins support signal transduction by elevating effective local concentrations of signaling proteins, and therefore theoretically an AKAP might support pRII dephosphorylation by CN in cells (Gildart et al., 2020). A-kinase anchoring protein 79 (AKAP79; rodent ortholog AKAP150, gene name AKAP5) is a prototypical mammalian anchoring protein with several features that indicate it could operate in part by increasing the effective protein concentration of pRII subunits for CN. AKAP79 can simultaneously anchor both CN and PKA (Coghlan et al., 1995). It contains an amphipathic anchoring helix (Gold et al., 2006; Kinderman et al., 2006) for binding RIl subunits, and a short linear 'PIAIIIT' CN anchoring motif (Dell'Acqua et al., 2002; Li et al., 2012). The two anchoring sites are separated by only $\sim 50$ amino acids in the primary sequence within the C-terminus of AKAP79 (Figure 1B). AKAP79 is localized in dendritic spines where it is required for anchoring RII subunits (Tunquist et al., 2008). The anchoring protein is necessary for both induction of long-term depression (LTD) of CA3-CA1 hippocampal synapses (Lu et al., 2008; Tunquist et al., 2008; Weisenhaus et al., 2010), and for CN-mediated dephosphorylation of NFAT (Kar et al., 2014; Murphy et al., 2014) - both processes that are driven by CN dephosphorylation of sites primed by PKA. Despite these characteristics, the possibility that AKAP79 could support pRII dephosphorylation by CN has been disregarded perhaps because paradoxically AKAP79 acts as a weak inhibitor for CN dephosphorylation of 20-mer peptides corresponding to the phosphorylated RII IS (Coghlan et al., 1995; Kashishian et al., 1998). We reasoned that these assays could be misleading since peptide substrates are not subject to anchoring alongside $\mathrm{CN}$ that occurs for full-length RII subunits. To resolve this issue, in this study we measured how AKAP79 alters CN activity towards full-length pRII subunits. We went on to determine if AKAP79 can reduce the fraction of dissociated $\mathrm{C}$ subunits in concert with $\mathrm{CN}$ using fluorescence-based assays supported by kinetic modeling, before substantiating our observations in hippocampal neurons.

\section{Results}

\section{AKAP79 enables CN to efficiently dephosphorylate RII subunits at physiological concentrations}

We set out to determine whether AKAP79 can increase CN dephosphorylation of full-length RII subunits phosphorylated at the IS. Using purified proteins (Figure 1-figure supplement 1), we compared ${ }^{32} \mathrm{P}$ release from either $\mathrm{pRIl \alpha}$ (Figure $1 \mathrm{C}$ ) or $\mathrm{pRII} \beta$ (Figure 1D). Thirty second reactions were initiated by addition of excess $\mathrm{Ca}^{2+} /$ calmodulin $(\mathrm{CaM})$ to $10 \mathrm{nM} \mathrm{CN}$ and $400 \mathrm{nM}$ pRII subunits. For pRIl $\alpha$ without AKAP79, phosphate was released from only $0.36 \% \pm 0.13 \%$ of the subunits (black, Figure 1C). Inclusion of full-length AKAP79 in the reaction mix increased phosphate release by 12.4fold $\left(P=7.4 \times 10^{-6}\right)$ to $4.52 \% \pm 0.26 \%$ pRIl $\alpha$ subunits (light blue, Figure $1 C$ ). Removing the PIAIIIT anchoring sequence in AKAP79 $(\triangle \mathrm{CN})$ returned dephosphorylation to a baseline level of $0.26 \% \pm$ $0.06 \%$ (gray, Figure 1C), consistent with a mechanism in which anchoring of CN adjacent to pRII subunits enhances the rate of dephosphorylation. Similar results were obtained for pRII $\beta$, with addition of AKAP79 increasing phosphate release 16.3-fold $\left(p=3.0 \times 10^{-6}\right)$ from $0.34 \% \pm 0.13 \%$ (black, Figure $1 D$ ) to $5.49 \% \pm 0.17 \%$ (dark blue, Figure 1D). Ablating the CN anchoring site in AKAP79 also reduced phosphorylation to a baseline level of $0.2 \% \pm 0.02 \%$ for this isoform (gray, Figure 1D).

We next measured $\mathrm{CN}$ activity toward pRII over a range of pRII concentrations. We compared activity towards pRII subunits alone or in complex with a fragment of AKAP79 (AKAP79 ${ }_{\text {c97 }}$ ) encompassing positions 331-427 that includes the CN and RII subunit anchoring sites. Working with this stable highly-expressed construct enabled us to purify sufficient quantities of pRIl $\alpha-A K A P 79_{c 97}$ and 


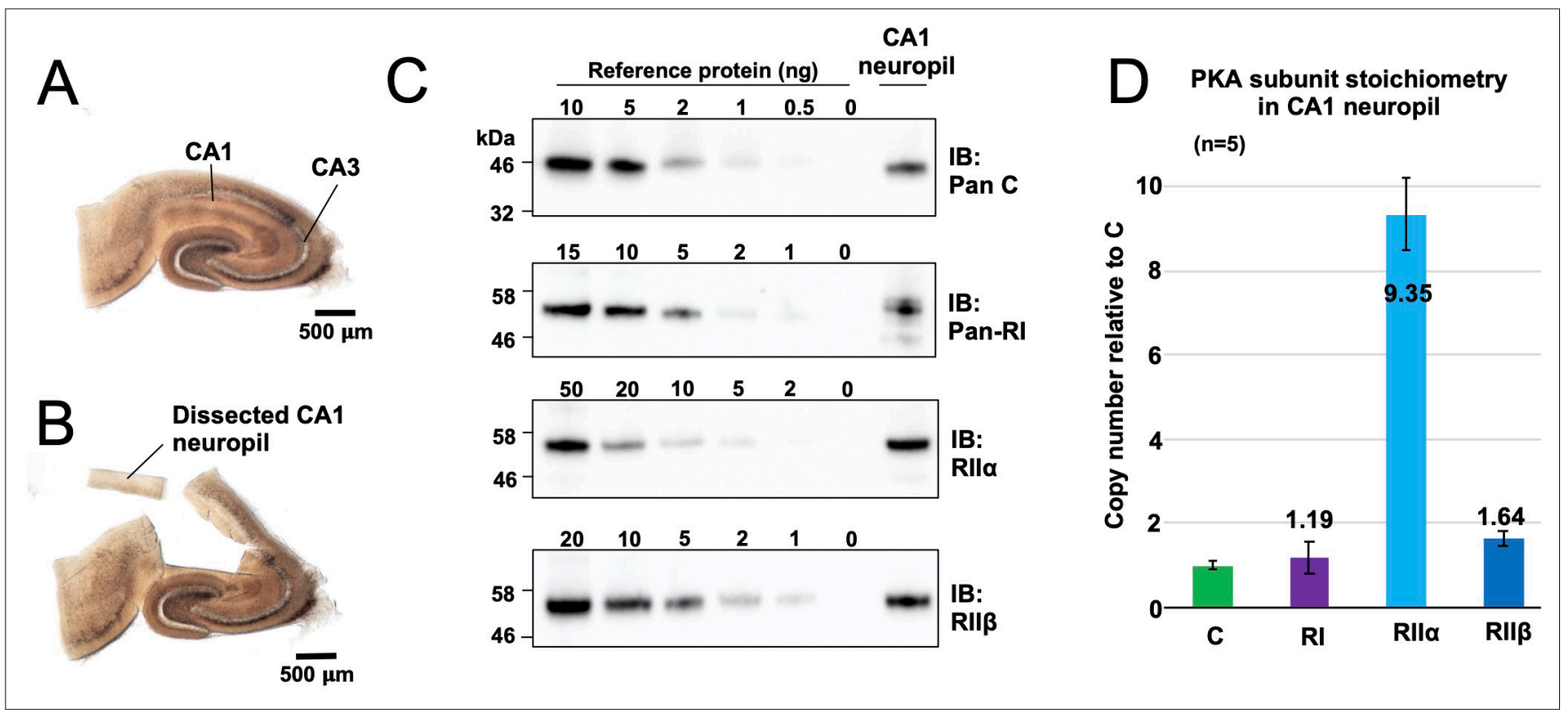

Figure 2. Quantitation of PKA subunits in CA1 neuropil. Images of a P17 rat hippocampal slice before (A) and after (B) micro-dissection of the CA1 neuropil layer. (C) Immunoblots of CA1 neuropil extract for PKA subunits. Extracts were run alongside reference amounts of the relevant purified PKA subunit in each immunoblot (Figure 2-figure supplement 1). In each case, $15 \mu \mathrm{g}$ total protein extract was run alongside the reference series, with the exception of the anti-C immunoblot (10 $\mu$ g extract). (D) Copy numbers of PKA subunits in rat CA1 neuropil normalized to $C$ subunits.

The online version of this article includes the following figure supplement(s) for figure 2:

Source data 1. Quantitative immunoblotting.

Figure supplement 1. Reference curves for quantitation of PKA subunits in CA1 neuropil.

pRIIß-AKAP79 ${ }_{\text {c97 }}$ complexes (Figure 1-figure supplement $1 C \& D$ ) to sample concentrations up to $5 \mu \mathrm{M}$. In complex with AKAP79 ${ }_{\mathrm{c} 97}$, both $\mathrm{pRIl \alpha}$ and $\mathrm{pRII} \beta$ acted as relatively high affinity substrates of CN. pRIl $\alpha-A K A P 79_{\text {c97 }}$ (light blue, Figure 1E) was dephosphorylated with a half-maximal concentration $\left(K_{m}\right)$ of $1.36 \pm 0.16 \mu \mathrm{M}$ and turnover number $\left(k_{\text {cat }}\right)$ of $0.45 \pm 0.02 \mathrm{~s}^{-1}$, and pRIIß-AKAP79 ${ }_{c 97}$ with $K_{m}$ $=0.74 \pm 0.12 \mu \mathrm{M}$ and $\mathrm{k}_{\mathrm{cat}}=0.24 \pm 0.01 \mathrm{~s}^{-1}$. As expected, in the absence of the anchoring protein, pRIl $\alpha$ and $p R I I \beta$ subunits served as low affinity substrates for CN (black lines, Figure 1E \& F). For both isolated pRII isoforms, the relationship between phosphatase activity and pRII concentration was linear up to $20 \mu \mathrm{M}$ (Figure 1-figure supplement 2) - the highest concentration tested - indicative of a $\mathrm{K}_{\mathrm{m}}$ of greater than $20 \mu \mathrm{M}$. CN activity was very low $\left(<0.03 \mathrm{~s}^{-1}\right)$ at concentrations of $5 \mu \mathrm{M}$ pRII or lower. This is consistent with earlier studies that reported a $\mathrm{K}_{\mathrm{m}}$ of $94 \mu \mathrm{M}$ for $\mathrm{CN}$ dephosphorylation of a phosphorylated 19-mer peptide derived from the RIl $\alpha$ IS (Stemmer and Klee, 1994). We also compared CN activity toward para-nitrophenylphosphate (pNPP) and a peptide corresponding to the isolated phosphorylated RII inhibitor sequence (sequence DLDVPIPGRFDRRVpSVAAE) with and without variants of AKAP79 ${ }_{\mathrm{c} 97}$ (Figure 1-figure supplement 3). WT AKAP79 ${ }_{\mathrm{c} 97}$ enhanced CN activity toward pNPP by $\sim 65 \%$, and reduced its activity towards pRII phosphopeptide by $\sim 50 \%$, consistent with previous reports that AKAP79 acts as a weak inhibitor of CN activity toward this phosphopeptide (Coghlan et al., 1995; Kashishian et al., 1998). Enhanced CN activity toward pNPP in the presence of PxIxIT-type motifs that have the opposite effect on phosphopeptide dephosphorylation has also been observed previously (Grigoriu et al., 2013). Overall, our data are consistent with a mechanism in which AKAP79 enhances CN dephosphorylation of full-length RII subunits by increasing effective substrate concentration rather than by altering the inherent catalytic activity of the phosphatase.

To put our kinetic parameters for pRII dephosphorylation into a physiological context, we set out to determine accurate protein concentrations for PKA subunits in the CA1 neuropil where Schaffer collaterals from the CA3 region synapse onto CA1 dendrites (Figure 2A). These synapses are a leading prototype for understanding forms of LTD driven by CN following PKA priming (Bear, 2003). We collected hippocampal slices from 18 -day-old male Sprague-Dawley rats before micro-dissecting CA1 neuropil sections (Figure 2B). Following homogenization, concentrations of C, RIl $\alpha, \mathrm{R} I I \beta$, and 
RI subunits in the extracted protein were determined using quantitative immunoblotting by running extracts $(n=5)$ alongside reference concentrations of purified PKA subunits (Figure 2C, Figure 2figure supplement 1; Walker-Gray et al., 2017). We found that Rll $\alpha$ was by far the most predominant PKA subunit in the CA1 neuropil, accounting for $0.32 \% \pm 0.029 \%$ total protein content compared to $0.032 \% \pm 0.003 \%$ for $C$ subunits, $0.041 \% \pm 0.014 \%$ for $\mathrm{RI}$, and $0.06 \% \pm 0.006 \%$ for RII $\beta$. These numbers equate to a 9.4-fold higher molar abundance of Rll $\alpha$ subunits (light blue, Figure 2D) relative to $C$ subunits with $R I$ and RII $\beta$ present at similar levels to $C$ subunits. The predominance of the RIl $\alpha$ subunit is consistent with a previous imaging study of rodent hippocampus (Weisenhaus et al., 2010). Assuming that protein accounts for $8 \%$ of total rat brain weight (Clouet and Gaitonde, 1956), we estimated RII subunit concentrations of $5.9 \mu \mathrm{M}(\mathrm{R} \| \alpha)$ and $1.03 \mu \mathrm{M}$ (RII $\beta)$. These values fall within the range where $\mathrm{CN}$ efficiently dephosphorylates $\mathrm{pRII}$ only in the presence of AKAP79 (Figure 1E \& F). Taken together our data therefore indicate that AKAP79 greatly enhances CN activity toward phosphorylated RII subunits at physiological concentrations.

\section{AKAP79 enables calcineurin to suppress type II PKA activity}

Given that AKAP79 supports rapid pRII dephosphorylation by CN, we hypothesized that the AKAP could enable $\mathrm{CN}$ to directly reduce the fraction of dissociated $\mathrm{C}$ subunits in mixtures of RII and C subunits. To test this hypothesis, we utilized purified A-kinase activity reporter 4 (AKAR4) (Figure 3A). PKA phosphorylation at threonine within the reporter's central 'LRRATLVD' motif leads to a conformational change that increases FRET efficiency between the terminal fluorescent proteins (Figure 3A; Depry et al., 2011). All AKAR4 experiments were performed using purified protein mixtures in 96-well plates. For each recording, three baseline $520 / 485 \mathrm{~nm}$ emission ratios were measured prior to injection of ATP and the desired concentration of CAMP into the protein mixture to initiate phosphorylation. Emission ratios were collected once every $5 \mathrm{~s}$ thereafter. In calibration experiments with AKAR4 and different concentrations of $\mathrm{C}$ subunit only (Figure 3-figure supplement 1A), we found that the initial rate of AKAR4 phosphorylation had a close to linear relationship to $C$ subunit concentration up to $400 \mathrm{nM} \mathrm{C}$ subunit (Figure 3-figure supplement 1B). Full AKAR4 phosphorylation increased the emission ratio by 72 \% (Figure 3-figure supplement 1A), consistent with previous studies (Depry et al., 2011). Importantly, supplementing these reactions with $1.5 \mu \mathrm{M}$ activated $\mathrm{CN}$ had no detectable effect on AKAR4 phosphorylation rates, indicating that the phosphatase cannot efficiently dephosphorylate the reporter (Figure 3-figure supplement 1C \& D). In comparison, supplementation with $1.5 \mu \mathrm{M}$ protein phosphatase 1 (PP1) reduced the phosphorylation rate by $\sim 7$ - fold (Figure 3 -figure supplement $2 \mathrm{~A}$ \& B). Phosphatase assays using pre-phosphorylated AKAR4 confirmed that CN exhibits very limited activity towards the reporter (Figure 3-figure supplement 2C \& D), such that the reporter is well suited for experiments focusing on direct suppression of PKA activity by CN.

Next, we assembled purified protein mixtures with the aim of mimicking signaling involving PKA, $\mathrm{CN}$, and AKAP79 in CA1 dendritic spines. RIl $\alpha, \mathrm{RI} \beta$, and C subunits were included at concentrations determined in CA1 neuropil extracts (Figure 2). CaM was added at a molar excess of $5 \mu \mathrm{M}, \mathrm{CN}$ at $1.5 \mu \mathrm{M}$ (Goto et al., 1986), and AKAP79 ${ }_{\mathrm{c} 97}$ - when included - at half the concentration of total RII subunits (summarized in Figure 3B). RI subunits were omitted since they are not thought to be present in dendritic spines (Ilouz et al., 2017; Tunquist et al., 2008), and because the RI inhibitor site is not phosphorylated so cannot be regulated by $\mathrm{CN}$. We first monitored AKAR4 phosphorylation in reactions containing RIl $\alpha, \mathrm{RII}, \mathrm{C}$, and CaM (black, Figure $3 \mathrm{C}$ ). Increasing the concentration of cAMP injected alongside ATP raised rates of AKAR4 phosphorylation as expected (black bars, Figure 3D). Supplementing the reactions with $\mathrm{CN}$ led to small but consistent decreases in the rate of AKAR4 phosphorylation at all cAMP concentrations (blue, Figure 3C \& D). Rates were determined between 30 and $90 \mathrm{~s}$ in the linear early phase that followed a brief $\sim 15$ second delay, with the exception of the lowest two cAMP concentrations $(0$ and $100 \mathrm{nM})$, where relatively slow rates were calculated between 30 and $330 \mathrm{~s}$. Additional supplementation with AKAP79 ${ }_{\mathrm{c} 97}$ markedly decreased the rate of AKAR4 phosphorylation (red, Figure 3C). For example, with $1 \mu \mathrm{M}$ cAMP activation, addition of both CN and the AKAP reduced the initial rate of AKAR4 phosphorylation by 2.8 -fold from $18.9 \pm 0.6$ to $6.7 \% \pm 0.8 \%$ per minute ( $p=0.0007$, black and red bars, Figure 3D). To confirm that AKAP79 enables CN to suppress PKA activity by anchoring it alongside RII subunits, we investigated the effect of removing either the CN (positions 337-343) or PKA (391-400) anchoring sites. At $1 \mu$ M cAMP activation, addition of wild-type (WT) AKAP79 ${ }_{\mathrm{c} 97}$ (red, Figure 3E \& F) reduced the initial rate of AKAR4 phosphorylation by 


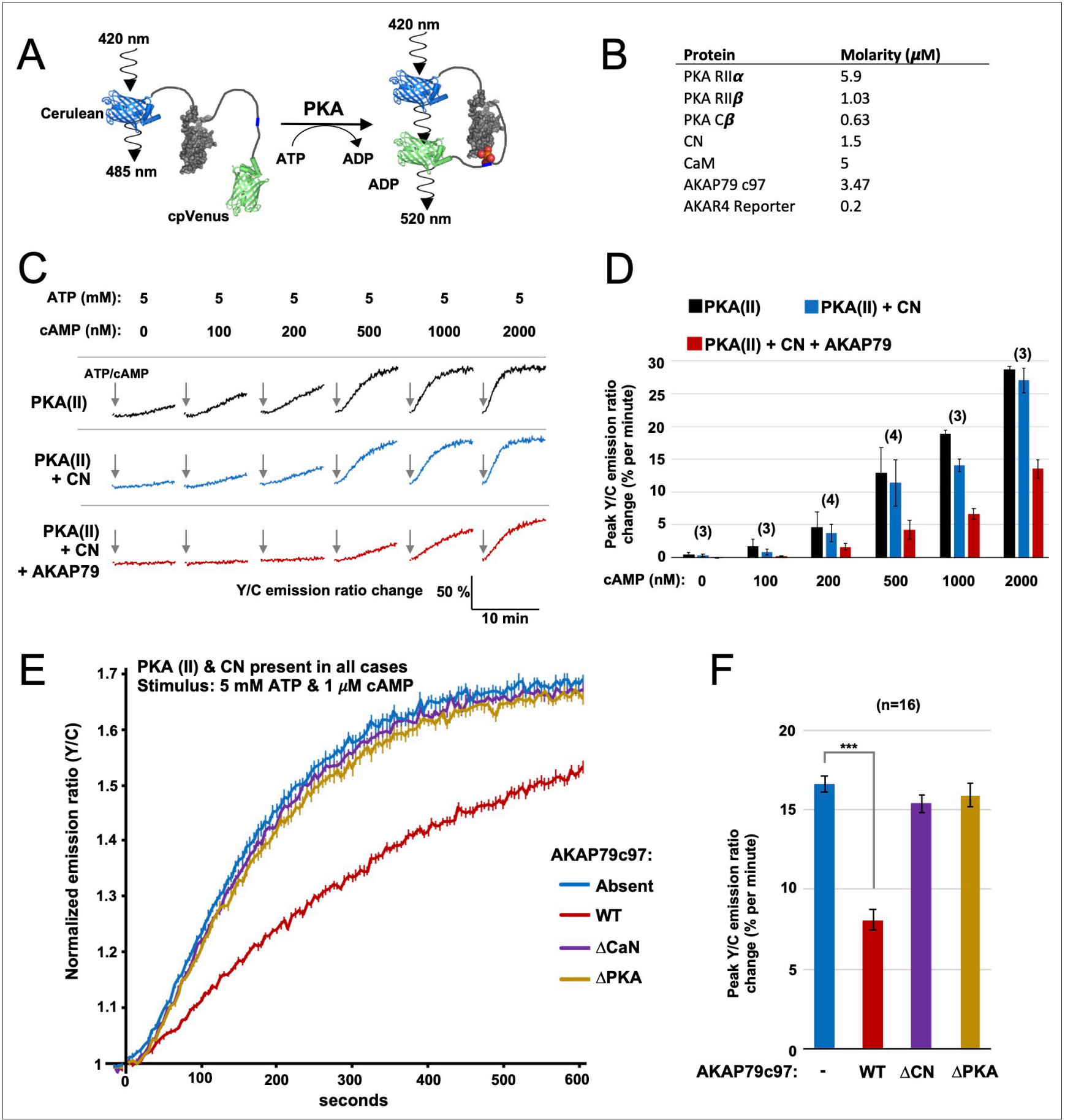

Figure 3. FRET-based PKA activity measurements. (A) AKAR4 mechanism: phosphorylation of the sensor by PKA is detected as an increase in FRET between the terminal fluorescent proteins. (B) Concentrations of proteins used for in vitro AKAR4 assays. Different experiments utilized different mixtures of these proteins but always at these concentrations. (C) Representative AKAR4 traces showing change in $520 \mathrm{~nm} / 485 \mathrm{~nm}$ (Y/C) emission ratio over time after injection of different concentrations of cAMP in tandem with 5 mM ATP. All protein mixtures included AKAR4, type II PKA (RIl $\alpha$, RII $\beta, C$ ), and CaM. Experiments were performed with either no further additives (top row, black), with CN added (middle row, blue), or with both CN and AKAP79 997 added (bottom row, red). ATP/cAMP injections are indicated by arrows. (D) The chart shows peak rates of emission ratio change for the recordings shown in the preceding panel. $n$ values are stated above the columns. (E) For these recordings, type II PKA, CN, and CaM were included in all cases. Phosphorylation was initiated by injection of $5 \mathrm{mM}$ ATP and $1 \mu \mathrm{M} c \mathrm{AMP}$ at $\mathrm{t}=0$. Averaged responses \pm standard error (SE) are shown with no further additives (blue), or when either WT (red), $\triangle \mathrm{CN}$ (purple), or $\triangle \mathrm{PKA}$ (gold) variants of AKAP79 ${ }_{\mathrm{c} 97}$ were included. (F) Peak rates (calculated between 30 and $90 \mathrm{~s}$ ) for the responses shown in the preceding panel. Statistical comparisons were performed using two-tailed unpaired Student $t$-tests. ${ }^{\star \star \star} \mathrm{p}<$ 0.001 .

Figure 3 continued on next page 
Figure 3 continued

The online version of this article includes the following figure supplement(s) for figure 3 :

Source data 1. Rates of AKAR4 phosphorylation in purified protein mixtures.

Figure supplement 1. AKAR4 reference measurements with PKA catalytic subunit.

Figure supplement 1-source data 1. Rates of AKAR4 phosphorylation with $C$ subunit alone.

Figure supplement 2. Comparison of $\mathrm{CN}$ and PP1 activity towards AKAR4.

Figure supplement 2-source data 1. Comparison of CN and PP1 activity toward PAKAR4.

2.06-fold $\left(p=2.7 \times 10^{-11}\right.$ ) compared to supplementation with only CN (blue). Similar AKAR4 responses were obtained when either the AKAP was omitted altogether (blue, Figure 3E \& F), or if either the CN (purple) or PKA (orange) anchoring sites in the AKAP were removed. Overall, these AKAR4 measurements reveal that AKAP79 enables $\mathrm{CN}$ to robustly decrease type II PKA activity by anchoring the two enzymes together.

\section{Mechanistic basis of PKA suppression by calcineurin and AKAP79}

We next aimed to quantify how AKAP79 and CN changed the fraction of free C subunits in our reaction mixtures. To estimate this, we cross-referenced rates of AKAR4 phosphorylation recorded in the 'spine mimic' reaction mixtures (Figure 3C \& E) to the reference curve $(r=0.998)$ obtained with only C subunits (Figure 3-figure supplement 1B). We focused on determining free $C$ subunit concentrations during the early period of linear change (30-90 s for cAMP concentrations of $0.2 \mu \mathrm{M}$ and above) where we assume the underlying kinetics are close to equilibrium. We calculated free $C$ subunit concentrations following this approach using all available data between 0 and $2 \mu \mathrm{M}$ cAMP (Figure 3figure supplement 1E). The calculated proportion of $\mathrm{C}$ subunits that are dissociated at different cAMP concentrations are shown for type II PKA+ CaM either alone (black, Figure 4A), with CN (blue, Figure 4B), or with both CN and AKAP79 ${ }_{\mathrm{c} 97}$ (red, Figure 4C). Together, AKAP79 and CN reduced the proportion of free $\mathrm{C}$ subunits at equilibrium across the cAMP concentration range including from 47.8 \pm 1.5 to $20.2 \% \pm 0.8 \%$ at $1 \mu \mathrm{M}$ cAMP, and from $65.7 \pm 1.1$ to $33.2 \% \pm 3.3 \%$ at $2 \mu \mathrm{M}$ cAMP (Figure $4 \mathrm{~A}$ \& C). The effect of adding CN alone was limited (Figure 4B), consistent with the much lower activity of the phosphatase towards pRII subunits in the low micromolar range (Figure 1E \& F).

To understand at a deeper level how CN and AKAP79 reduce the fraction of free $\mathrm{C}$ subunits, we updated and extended a kinetic model (Buxbaum and Dudai, 1989) that takes into account transitions between pRII (left-hand square, Figure 4D) and unphosphorylated RII subunits (right-hand square). The extended model also incorporates AKAR4 binding to and phosphorylation by free C subunits. We used a Bayesian approach (Eriksson et al., 2019) to estimate parameter sets for the model that could fit data pooled from AKAR4 recordings obtained after stimulation with 0, 0.2, 1, and $2 \mu \mathrm{M}$ cAMP (Figure $3 C$ \& E). A log uniform prior parameter distribution was used as a starting point for the Bayesian method, where each parameter was allowed to vary three orders of magnitude around a default value (Supplementary file 1). The default values were taken from empirical data, including rates of pRII dephosphorylation determined in this study (Figure 1), and binding rates of C subunits to pRII and RII (Zhang et al., 2015). This parameter estimation approach resulted in approximately 15,000 parameter sets that could explain the experimental data (Figure 4E-G). Simulations using these parameter sets enabled us to predict concentration changes of individual states within the model that cannot be determined experimentally (first three columns, Figure 4-figure supplement 1). The model indicates that AKAP79 and $C N$ together shift $C$ subunit capture to the faster right-hand square sub-system (Figure 4D), driving down the fraction of free $C$ subunits and thereby reducing PKA activity.

\section{Mutation of the RIla IS phosphorylation site occludes PKA suppression by $\mathrm{CN}$}

The results of the preceding sections show that AKAP79 targeting of CN for direct suppression of PKA is a viable mechanism for LTD induction. Previously published studies in hippocampal slices involving genetic manipulation of AKAP150 (the rodent ortholog of AKAP79) are also consistent with this mechanism. Full AKAP150 knock-out (Lu et al., 2008; Tunquist et al., 2008; Weisenhaus et al., 2010), or AKAP150 knock-in with variants lacking either the PKA or CN anchoring sites (Jurado et al., 2010; 


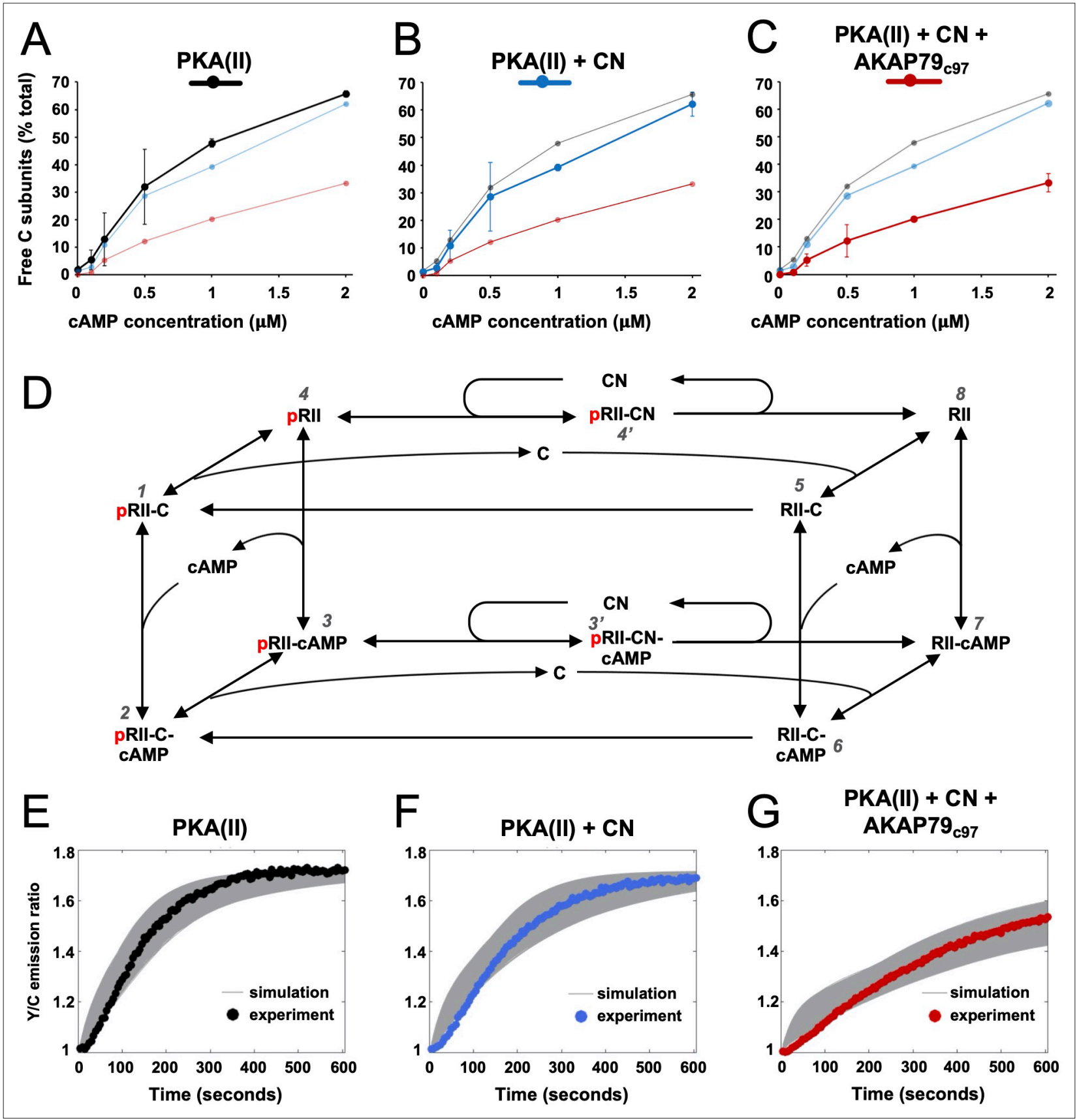

Figure 4. Kinetic analysis of PKA-CN-AKAP79 signaling. (A-C) Estimates of the average proportion of free $\mathrm{C}$ subunits between 30 and $90 \mathrm{~s}$ for type II PKA alone (black), with CN (blue), and with both CN and AKAP79 997 (red) following activation of the protein mixtures with a range of cAMP concentrations. (D) Reaction scheme used for modeling type II PKA regulation by CN. Each species within the scheme is numbered consistent with supporting data in figure in Supplementary file 1. (E-G) Model simulations for protein mixtures activated with $1 \mu \mathrm{M}$ cAMP are shown with the experimental data overlaid. Averaged values are shown for experimental data after pooling the data shown in Figure 3. Responses are shown for type II PKA alone $(\mathbf{E})$, with $\mathrm{CN}(\mathbf{F})$, and with both $\mathrm{CN}$ and $\mathrm{AKAP79}_{\mathrm{c97}}(\mathbf{G})$. A sample of the corresponding simulated responses are shown in grey. An 'error' threshold of 0.01 was used to accept curves as a good fit.

The online version of this article includes the following figure supplement(s) for figure 4:

Source data 1. Free $\mathrm{C}$ subunit calculations.

Figure supplement 1. Simulations of kinetic scheme species changes in concentration over time.

Figure supplement 2. Simulations of responses with different concentrations of cAMP. 


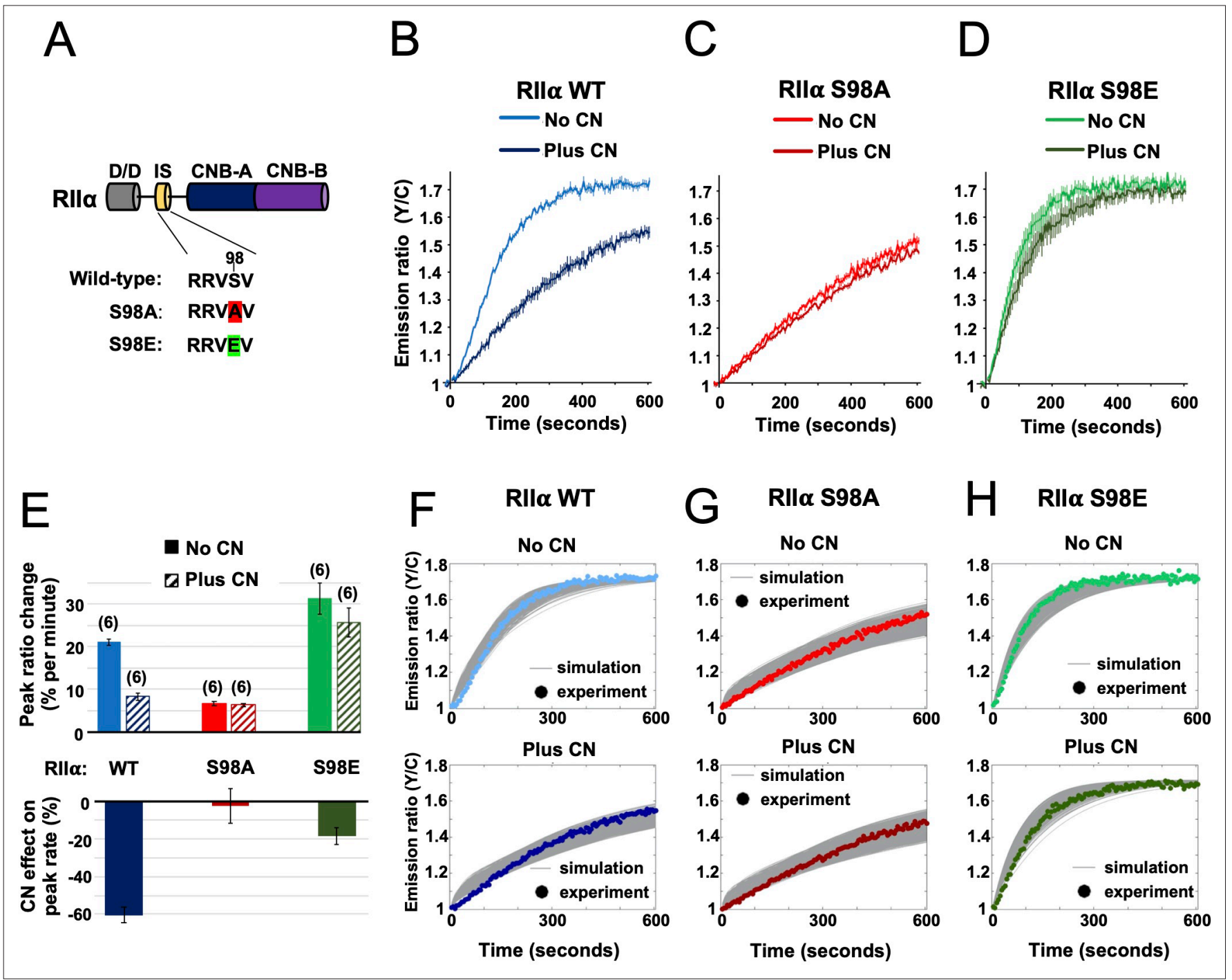

Figure 5. Characterization of RIl $\alpha$ IS phosphorylation site mutations. (A) RII subunit topology showing locations of the docking and dimerization domain ( $D / D$, gray), inhibitor sequence (IS, yellow), and tandem cyclic nucleotide binding domains (dark and light blue). S98A (red) and S98E (green) mutations in the IS are highlighted. (B-D) Comparison of AKAR4 emission ratio changes following $5 \mathrm{mM} \mathrm{ATP/1} \mu \mathrm{M}$ cAMP activation of protein mixtures containing either WT (B), S98A (C), or S98E (D) RII. $1.03 \mu \mathrm{M}$ RII $\beta$ was included in all cases. Measurements were collected either with or without CN in the reaction mixture. Averaged responses ( \pm SE) are shown for WT RIl with (dark blue) and without CN (light blue), S98A RIl with (dark red) and without (light red) CN, and RII S98E with (dark green) and without (light green) CN. (E) The upper bar chart shows peak rates (calculated between 30 and 90 s) for the responses shown in panels b-d. The effect of including $\mathrm{CN}$ in the reaction mixture for each Rll variant is shown in the lower bar chart. (F-H) Model predictions in the six conditions of panels b-d are shown in grey when simulating using the 'extended' model (see Materials and methods) and using the different parameter sets generated from the parameter estimation approach. The same parameters as retrieved using data shown in Figure 4 were used as a starting point for the simulations, but parameter sets were filtered based on data collected with RII S98A. Model predictions are shown alongside the corresponding experimental data collected with either WT (F), S98A (G), or S98E (H) RII in the reaction mix.

The online version of this article includes the following figure supplement(s) for figure 5 :

Source data 1. Rates of AKAR4 phosphorylation with mutant Rll $\alpha$ subunits.

Figure supplement 1. Space of parameters used in model fitting.

Sanderson et al., 2016), show that both AKAP150 anchoring sites are required for LTD induction. However, such approaches cannot distinguish between CN targeting to pRII subunits versus other substrates. If direct suppression of PKA activity by CN is essential for LTD induction, we reasoned that mutation of the IS phospho-acceptor S98 (Figure 5A) in the predominant RIla isoform would be expected to disrupt LTD induction in CA1 neurons. To confirm this presupposition before undertaking experiments in neurons, we re-ran AKAR4 experiments at $1 \mu \mathrm{M}$ cAMP substituting in either 
S98A or S98E RIla. For each RIl $\alpha$ variant (Figure 1-figure supplement 1H), we compared responses with or without CN, with WT RII $\beta$ and AKAP79 ${ }_{\text {c97 }}$ present in all cases. For WT RIl $\alpha$, addition of CN to the mixture decreased the peak rate of AKAR4 phosphorylation from $21.02 \pm 0.76$ (light blue, Figure $5 B$ ) to $8.24 \% \pm 0.79 \%$ per minute (dark blue). Substituting in RIl $\alpha$ S98A generated slow rates of AKAR4 phosphorylation in both cases $(6.30 \% \pm 0.44 \%$ per min with $\mathrm{CN}$, and $6.67 \% \pm 0.56 \%$ without, Figure $5 \mathrm{C}$ ). Conversely, the peak rate of AKAR4 phosphorylation was high regardless of the presence of $\mathrm{CN}$ for the S98E RIl $\alpha$ variant $(31.30 \% \pm 3.60 \%$ per $\min$ without $\mathrm{CN} ; 25.65 \% \pm 3.44 \%$ with CN, Figure 5D). Together, this data indicates that substituting in either mutant of RIl $\alpha$ in neurons would be expected to reduce LTD induction in neurons if direct suppression of PKA by CN is required in LTD induction (Figure 5E).

Before moving on to experiments in neurons, we used the data collected with RIl $\alpha$ variants to test the accuracy of our kinetic modeling. We ran simulations assuming that the S98A and S98E variants of RIl $\alpha$ would behave like dephosphorylated and phosphorylated forms of the regulatory subunit. Broadly, the simulations were in line with our experimental data and predicted that addition of CN would reduce PKA activity substantially more in the WT but not Rll $\alpha$ mutant conditions (Figure 4-figure supplement 1), with low and high PKA activities regardless of CN concentration for the S98A and S98E variants, respectively. The model predictions for the extent by which AKAR4 phosphorylation was depressed in the RIl $\alpha$ S98A system were, however, spread out depending on the specific parameter set (column 4-5, Figure 4-figure supplement 1). This implies that the WT data we used to constrain the model were not sufficient to precisely constrain the dynamics specifically for the unphosphorylated RII sub-system (right square, Figure 4D) To understand the characteristics of those parameter sets that also reproduced the RIl $\alpha$ S98A behavior, we filtered the parameter sets returned by the parameter estimation approach into two classes depending on whether they fit closely (blue, Figure 4-figure supplement 1) or not (red) to the acquired mutation data, yielding 526 parameter sets that fit closely to both the WT and mutation data. A pairwise coordinate plot (see Figure 5-figure supplement 1A) shows that, except for a few parameters, the two classes do not appear to be visually distinct with regard to kinetic rates. However, analysis and subdivision of the eight model dissociation constants $\left(K_{D}\right.$ 's) reveals interesting relationships (Figure 5-figure supplement 1B). Notably, as shown by the histograms and scatterplot for the $K_{D}$ for interaction between RII-C and CAMP $\left(K_{D} 56\right)$, and RII-CAMP and $C\left(K_{D} 76\right), K_{D} 56$ is most often relatively low within its range paired with a relatively high $\mathrm{K}_{\mathrm{D}} 76$ (Figure 5-figure supplement $1 C$ \& $D$ ) when accurately mimicing the biological workings of the PKA sub-system. This behavior may ensure that sufficient $C$ subunit is released with increasing cAMP in our model when the kinetics are restrained to the unphosphorylated RII sub-system, i.e when the RIla S98A mutation is introduced. Overall, simulations using unfiltered (top row, Figure 4-figure supplement 1) and filtered (Figure 5F-H) parameter sets show that the kinetic model closely reproduces the experimental data, especially when further constrained using data collected with RIl $\alpha$ S98A. Furthermore, the constrained simulations reproduce the experimental data collected at different CAMP concentrations (Figure 4-figure supplement 2). Taken together, experiments and simulations with S98A and S98E variants of RIl $\alpha$ show that either of these mutations should prevent AKAP79 and CN from switching $C$ subunit capture from the left-hand square subsystem to the faster right-hand square (Figure 4D). Therefore, either substitution would be expected to reduce LTD induction if the mechanism is important in vivo.

\section{Disruption of Rll $\alpha$ phosphorylation in CA1 neurons impedes chemical LTD}

To enable neuronal RIl $\alpha$ replacement experiments, we generated lentiviruses for shRNA-mediated knockdown of endogenous RIl $\alpha$ and simultaneous expression of shRNA-resistant RIl $\alpha$ variants in tandem with GFP. The lentiviruses contain an $\mathrm{H} 1$ promoter for expression of a highly effective shRNA targeted to RIl $\alpha$ (Figure 6A). A UbC promoter drives expression of replacement Rll $\alpha$ sequences in tandem with GFP, with an internal ribosome entry sequence (IRES2) between the coding sequences of the two proteins enabling expression of GFP. We validated the lentiviruses in dissociated rat primary hippocampal neurons by comparing the efficacy of five different lentiviruses. On day 7 in vitro (DIV7), we infected with control lentiviruses expressing either scrambled or shRIl $\alpha$ RNA, or with complete viruses for replacement of endogenous RIl $\alpha$ with either WT, S97A, or S97E (RIl $\alpha$ in rat is equivalent to S98 in human RIl $\alpha$ ). Neuronal protein extracts were collected on DIV14, and analyzed using 


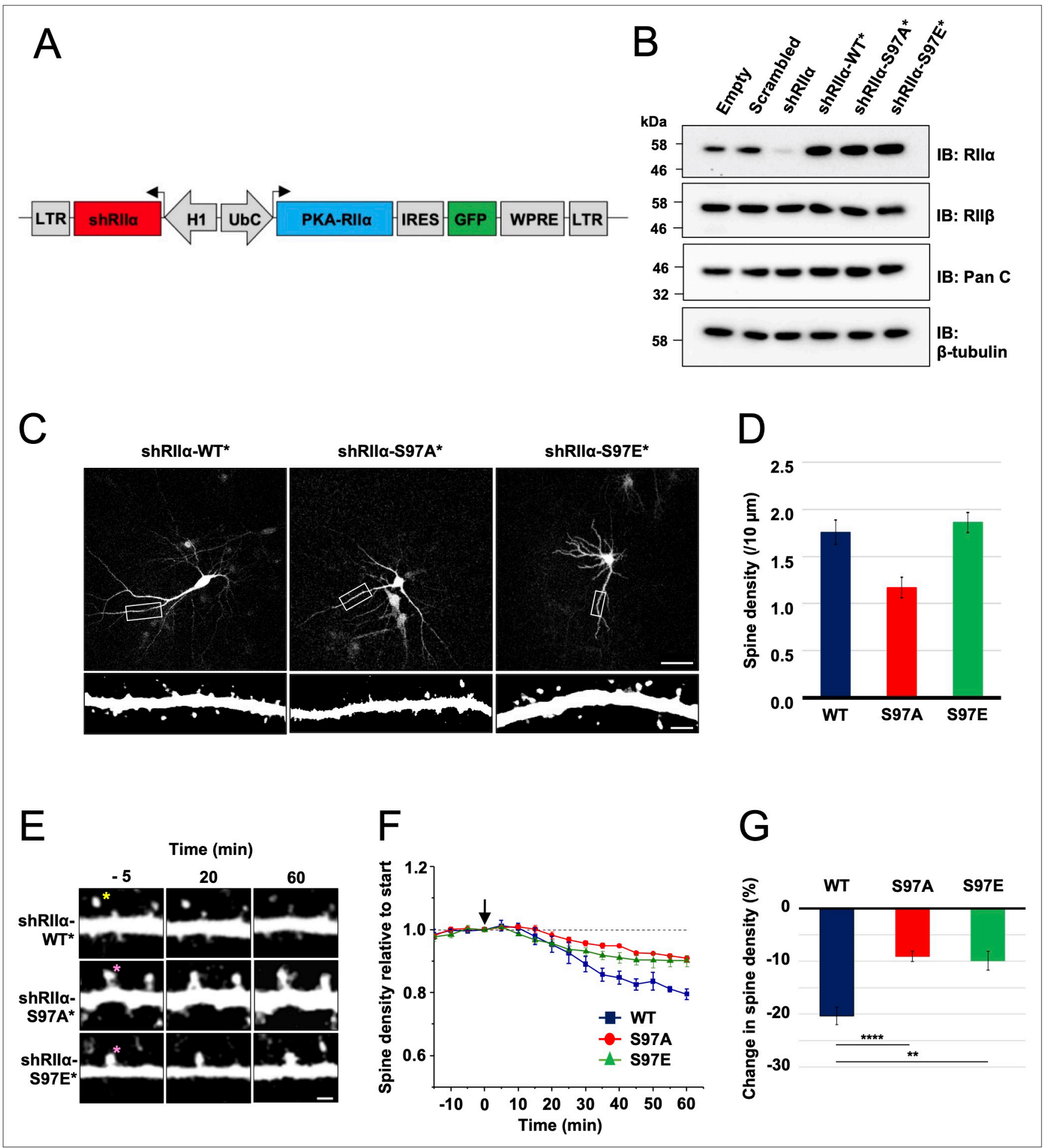

Figure 6. Lentivirus development and spine density imaging. (A) Schematic of the FUGW-H1-based lentiviral vector used to knock down and replace endogenous Rll $\alpha$ subunits in dissociated hippocampal cultures. (B) To validate lentiviruses, dissociated hippocampal neurons were infected on the seventh day in vitro (DIV7). Immunoblots are shown comparing neuronal extracts collected on DIV14 after infection with no virus, virus expressing scrambled shRNA only, shRIl $\alpha$ only, and the three complete lentiviruses for knockdown/replacement with either WT, S97A, or S97E RIl $\alpha$. (C) Representative live-cell images of lentivirus-infected primary hippocampal neurons at DIV14 expressing either WT, S97A, or S97E Rll $\alpha$. Scale bars correspond to $50 \mu \mathrm{m}$ (upper panels) and $5 \mu \mathrm{m}$ (lower panels). (D) Average spine density on hippocampal dendrites following lentiviral replacement of endogenous Rll $\alpha$. Data were averaged from 106 (WT), 97 (S97A), and 113 (S97E) neurons derived from seven rats for each condition, and are represented as mean \pm SE. Conditions were compared using one-way ANOVA with Turkey post-hoc tests. (E) Representative live-cell images showing dendritic spines in primary hippocampal neurons expressing either WT, S97A, or S97E replacement RIl $\alpha$ at three points before and after chem-LTD

Figure 6 continued on next page 
Figure 6 continued

(scale bar $=2.5 \mu \mathrm{m}$ ). Chem-LTD was induced at $\mathrm{t}=0$ with $20 \mu \mathrm{M}$ NMDA for $3 \mathrm{~min}$. The yellow asterisk indicates a spine that disappeared over the course of the protocol whereas the pink asterisks indicate spines that did not. (F) Plot showing average changes in spine density ( \pm SE) in primary hippocampal neurons expressing either WT (dark blue), S97A (red), or S97E (green) Rll $\alpha$. (G) Average changes in spine density \pm SE 1 hr after induction of chem-LTD are shown for neurons expressing WT (dark blue, $n=5$ ), S97A (red, $n=5$ ), and S97E (green, $n=4$ ) Rll $\alpha$ variants as shown in the preceding two panels. Statistical comparisons were performed by two-way ANOVA followed by Bonferroni's post-hoc test. ${ }^{* \star} p<0.01,{ }^{\star \star \star} p<0.001$.

The online version of this article includes the following figure supplement(s) for figure 6:

Source data 1. Spine density quantitation.

immunoblotting. Anti-Rlla immunoblotting (top row, Figure 6B) confirmed effective suppression of endogenous Rll $\alpha$ with shRlla (lane 3) but not scrambled RNA (lane 2), and strong expression of the replacement sequences (lanes 4-6). Expression of PKA C (row 2, Figure 6B) and RII $\beta$ subunits (row 3) was not affected by lentiviral infection in any case. Blocking PKA activity with $\mathrm{H} 89$ is known to prevent growth of new spines, whereas stimulating PKA with forskolin increases spine formation (Kwon and Sabatini, 2011). Replacing Rlla with the S97A variant - which has lower PKA activity regardless of $\mathrm{CN}$ activity (Figure 5F) - would therefore be expected to lead to a reduction in spines. To test this, we imaged dendritic spines on primary hippocampal neurons expressing either WT (left panel, Figure 6C), S97A (middle panel), or S97E (right panel) RIl $\alpha$. Consistent with a role for PKA in spinogenesis, spine density was reduced by $33.5 \%(p=0.002)$ in neurons expressing the S97A variant to $1.17 \pm 0.11$ spines per $10 \mu \mathrm{m}$ compared to $1.76 \pm 0.12$ for WT Rll $\alpha$. Spine density for the S97E variant was similar to WT at $1.86 \pm 0.11$ spines/10 $\mu \mathrm{m}$ (Figure 6D).

To test whether the two substitutions at Rlla S97 affect LTD, we monitored changes in dendritic spine number during chemical LTD - a model of long-term synaptic depression that can be applied in dissociated neuronal cultures. Bath application of $20 \mu \mathrm{M}$ NMDA for 3 min triggered a steady reduction in spine density (Figure 6E, top row) in neurons expressing WT Rlla as expected (Zhou et al., 2004), reaching a $20.4 \% \pm 1.6 \% \%$ reduction in spines after one hour (blue, Figure $6 F$ ). In comparison, spine loss was attenuated in neurons expressing either the S97A (Figure 6E, middle row) or S97E (bottom row) Rlla variants. Spine numbers were reduced by only $9.07 \% \pm 0.96 \%$ in neurons expressing Rlla S97A (red line, Figure 6F), and by $9.90 \% \pm 1.8 \%$ for the S97E variant (green line). The residual LTD in both conditions may correspond to action of $\mathrm{CN}$ on substrates other than pRII subunits, and limited suppression of PKA activity through CN dephosphorylation of the relatively small number of WT RII subunits that are present in all cases. Overall, attenuation of spine loss in neurons expressing either S97A ( $p=0.00046$ ) or S97E ( $=0.0014)$ Rlla compared to WT subunits is consistent with an important role for direct PKA activity suppression by CN during the induction of LTD.

\section{Discussion}

The observations in this study support a revised mechanism for $\mathrm{CN}$-mediated long-term depression in CA1 model synapses. AKAP79/150 is critical for anchoring PKA in dendritic spines (Tunquist et alo, 2008; Weisenhaus et al., 2010) through association with RIl subunits, which are the predominant neuronal PKA subunit in $\sim 11$ fold molar excess of $C$ subunits in the CA1 neuropil (Figure 2D). Imaging studies (Ilouz et al., 2017; Weisenhaus et al., 2010) are consistent with our quantitative immunoblotting data, which show that RIl $\alpha$ is the major RII isoform in the CA1 neuropil. pRII dephosphorylation is limited prior to $\mathrm{Ca}^{2+}$ stimulation (Figure 7A), enabling a tonic level of dissociated $\mathrm{C}$ subunits sufficient to basally phosphorylate postsynaptic substrates in dendritic spines such as GluA1 subunits of AMPAtype glutamate receptors (Bear, 2003). LTD is brought about by CN (Mulkey et alo, 1994), which is activated by $\mathrm{Ca}^{2+}$ entering spines through NMDA-type glutamate receptors (Figure 7B). AKAP79/150 contains a 'PIAllIT' CN anchoring motif that is necessary for LTD (Jurado et al., 2010; Sanderson et al., 2012). In addition to potentially targeting $C N$ to postsynaptic substrates including GluA1 subunits, the PIAIIIT anchoring motif positions $\mathrm{CN}$ adjacent to pRII subunits where it can efficiently dephosphorylate them (Figure 7B). This enables $\mathrm{CN}$ to increase the concentration of dephosphorylated RIl species (blue spheres in the kinetic scheme shown in Figure 7B) thereby directly suppressing PKA activity by increasing the rate of PKA C subunit capture. Consistent with this mechanism, blocking regulation of Rll phosphorylation state by introducing mutations that mimic either the phosphorylated or dephosphorylated forms of the IS reduces LTD in cultured hippocampal neurons. 

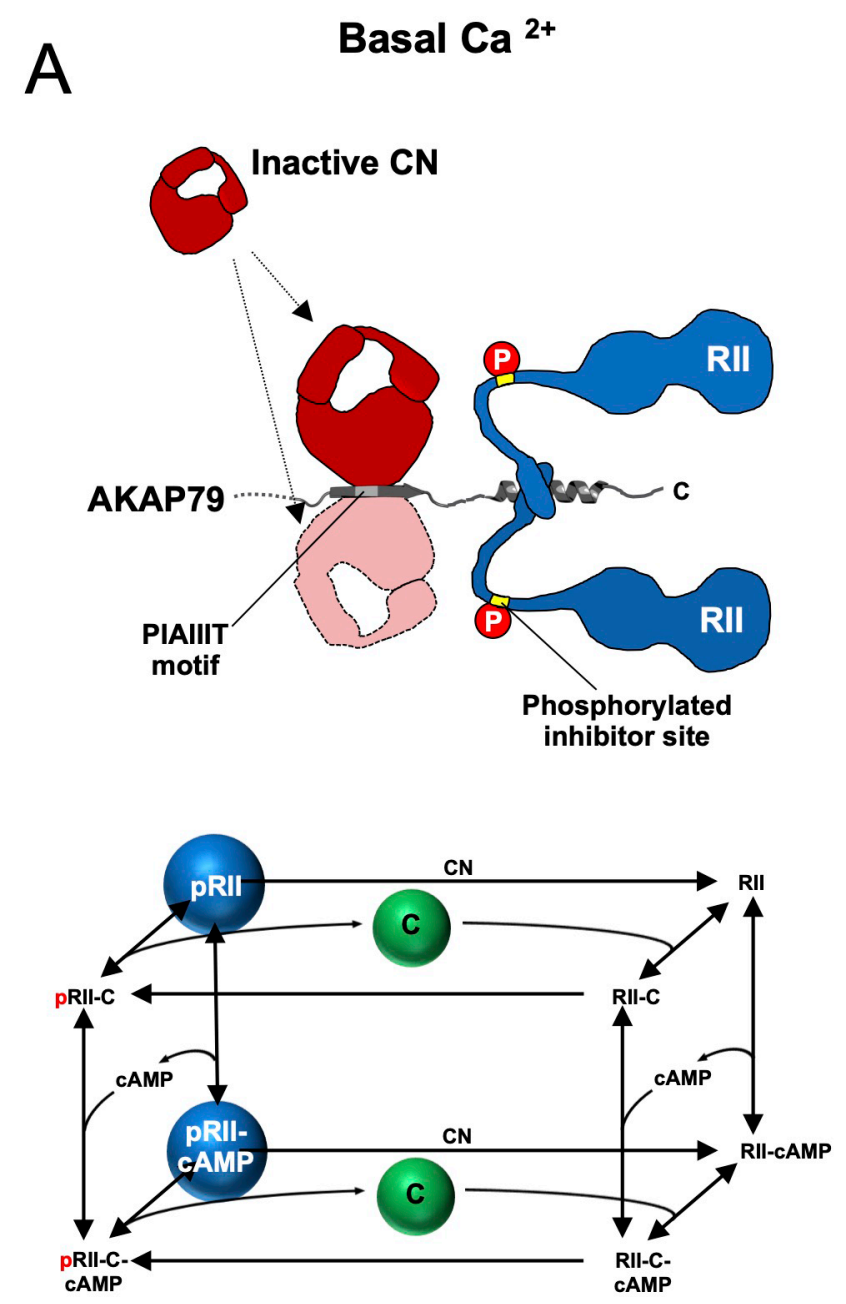
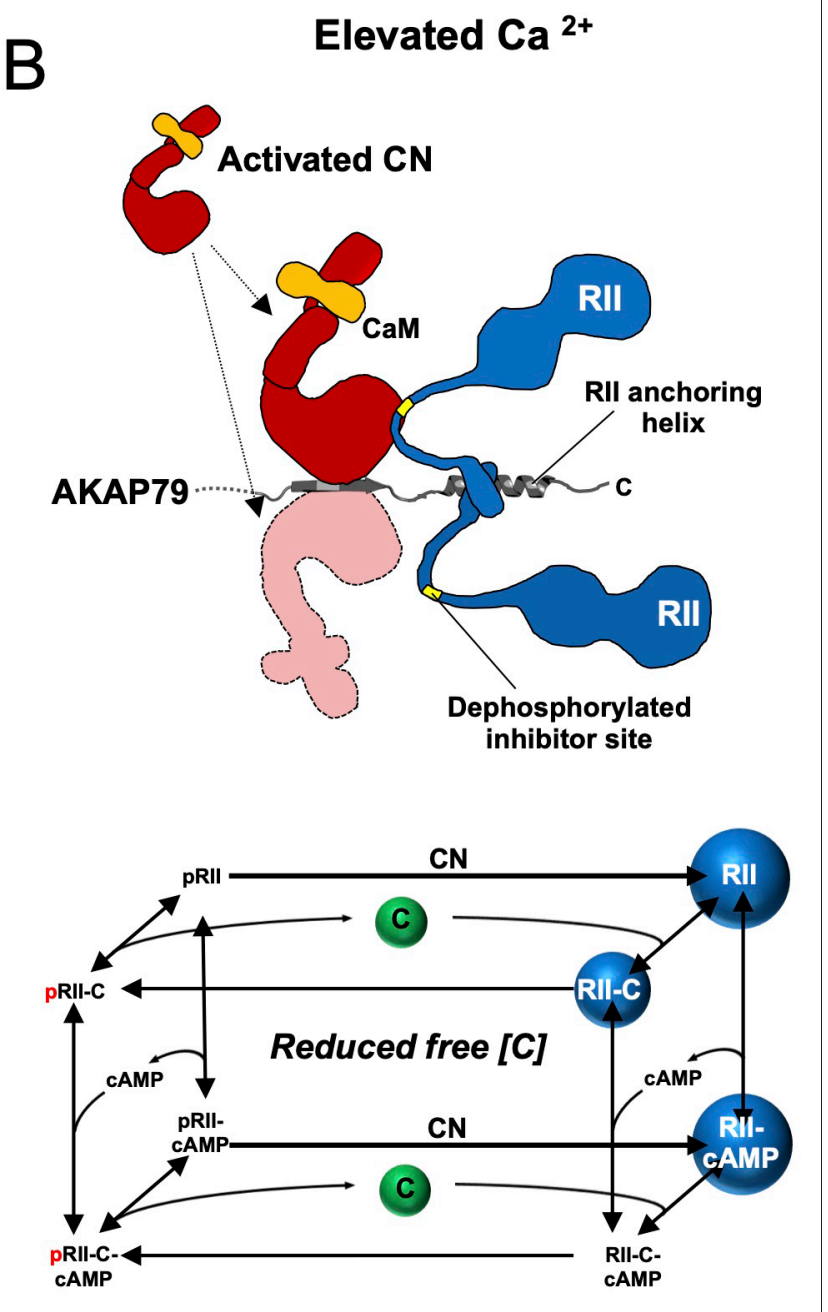

Figure 7. Summary model of PKA suppression by CN within the AKAP79 complex. Structural and kinetic models (upper and lower panels, respectively) of signaling within the AKAP79 complex are shown under conditions of either low (A) or elevated $\mathrm{Ca}^{2+}$ (B). Elevated $\mathrm{Ca}^{2+}$ triggers $\mathrm{CN}$ (red) dephosphorylation of pRII (blue) which shifts $\mathrm{C}$ subunit capture from the left-hand square of the kinetic scheme to the right-hand square which features dephosphorylated forms of RII. The overall effect is a reduction in the concentration of free $\mathrm{C}$ subunits. The most abundant forms of RII under the two conditions are highlighted by blue spheres.

Our discovery that CN can directly suppress PKA activity in the AKAP79 complex reconciles three aspects of AKAP79 structure and function that had been enigmatic and paradoxical. First, previous studies showed that AKAP79 acts as a weak inhibitor of CN towards peptide substrates including a 20-mer peptide encompassing the phosphorylated RII IS (Coghlan et al., 1995; Kashishian et al., 1998), apparently at odds with the functional requirement for the anchoring protein in targeting CN to bring about LTD. We show that the key substrate for CN is likely to be full-length pRII subunits, and that in fact AKAP79 enhances the activity toward pRII at physiological concentrations by more than 10-fold. A second enigmatic feature of AKAP79 is its CN anchoring motif, PIAIIIT, which includes an additional central residue compared to the typical PxIxIT motif (Roy and Cyert, 2009). In a crystal structure of $\mathrm{CN}$ in complex with a peptide corresponding to AKAP79 positions 336-346, the additional leucine supports simultaneous binding of two copies of CN on either side of the motif (Li et al., 2012). Native mass spectrometry measurements of a purified AKAP79-CN-CaM-RIl $\alpha$ D/D complex also support a stoichiometry of 2 CN to 1 AKAP79 (Gold et al., 2011), although solution measurements indicate that when full-length RII subunits are bound to AKAP79, only one copy of CN can bind at a time (Li et al., 2012; Nygren et al., 2017). One possible explanation for this behavior is that CN binds transiently to either side of the AKAP79 PIAIIIT motif enabling it to access both protomers of RII anchored to AKAP79 for efficient pRII dephosphorylation (cartoon representations in Figure 7). 
This idea is consistent with data showing that mutating the PIAIIIT motif to a high-affinity canonical PxIxIT motif impairs the function of the phosphatase (Li et al., 2012), although it should be noted that it is not possible to determine whether two-sided CN binding to AKAP79 is necessary using the data presented here. Third, existing models of AKAP79 function assume that $\mathrm{CN}$ anchored to AKAP79 overcomes PKA phosphorylation at substrates with no reduction in PKA phosphorylation rate. In our revised mechanism, CN directly suppresses PKA activity when removing phosphate from substrates primed by PKA thereby avoiding energetically costly ongoing futile cycling of phosphorylation and dephosphorylation by PKA and $\mathrm{CN}$ at these sites.

A challenge in the future will be to understand how the mechanism uncovered here relates to the full complexity of AKAP79 function. AKAP79 is directly regulated by $\mathrm{Ca}^{2+} / \mathrm{CaM}$, which binds to a 1-47-8 hydrophobic motif (Patel et al., 2017) starting at position W79. Binding of $\mathrm{Ca}^{2+} / \mathrm{CaM}$ releases AKAP79 from the postsynaptic membrane (Dell'Acqua et al., 1998) and alters the conformation of the signaling complex by triggering formation of a second interface between $\mathrm{CN}$ and AKAP79 that involves an LxVP-type motif in AKAP79 (Gold et al., 2011; Nygren et al., 2017). Furthermore, metal ions including $\mathrm{Ca}^{2+}$ alter rates of substrate binding and product release from PKA $\mathrm{C}$ subunits (Knape et al., 2015; Zhang et al., 2015). Therefore, it will be important to understand the sensitivity of $\mathrm{CN}$ suppression of PKA activity to $\mathrm{Ca}^{2+}$ signals. Membrane targeting sequences regulate several components of the AKAP79 signaling complex. Myristylation of $C$ subunits is important for limiting their diffusion rate in dendritic spines and concentrating PKA activity at the cell membrane (Tillo et al., 2017; Xiong et al., 2021). Localization of AKAP79 is also regulated by palmitoylation at C36 and C139 (Delint-Ramirez et al., 2011; Keith et al., 2012). Palmitoylation is required for endosomal localization of AKAP79, and AKAP79 depalmitoylation and synaptic removal is additionally regulated by CaMKII (Woolfrey et al., 2018). Our work suggests that removal of AKAP79 from synapses might be synchronized with accumulation of inhibited $C$ subunits in the AKAP79 complex. Given that RII subunits greatly outnumber $C$ subunits, movement of $C$ subunits between different RII sub-populations, including Rll subunits anchored to MAP2 in dendritic shafts (Tunquist et alo, 2008), should also be considered along with PDEs that can terminate CAMP signals with high spatiotemporal precision (Bock et al., 2020; Tulsian et al., 2017). Non-dissociative activation of anchored type RII PKA has been put forward as an alternative mechanism to explain localised PKA activity (Smith et al., 2017). Current evidence indicates that $C$ subunits do dissociate in neurons upon elevation of cAMP (Gold, 2019; Mo et al., 2017; Tillo et al., 2017), but it is important to note that suppression of PKA by pRII dephosphorylation is compatible with non-dissociative models of PKA activation and this might occur in certain physiological settings. AKAP79 is a highly multivalent protein - other notable documented interaction partners include protein kinase $\mathrm{C}$ (Hoshi et al., 2010) and the $\mathrm{Ca}^{2+}$-activated cyclase AC8 (Baldwin and Dessauer, 2018; Zhang et al., 2019). Oscillations of $\mathrm{Ca}^{2+}$, cAMP, and PKA activity have been observed in pancreatic $\beta$-cells (Hinke et al., 2012; Ni et al., 2011), and knockout of AKAP150 leads to the loss of cAMP oscillations in $\beta$-cells upon stimulation with insulin (Hinke et al., 2012). CN dephosphorylation of pRII subunits bound to AKAP79 is likely to play a role in oscillatory patterns of PKA activity, and it will be important to understand how this mechanism underlies responses to short-lived and oscillatory changes in $\mathrm{Ca}^{2+}$ and cAMP concentration.

In this combined experimental-computational study, we focused on AKAP79 signaling in dendritic spines on the basis that this could serve as a prototype for understanding a potentially widespread non-canonical mechanism for altering PKA. In addition to its role in dendritic spines, AKAP79 regulates many different membrane channels and receptors following $\mathrm{Ca}^{2+}$ influx through a variety of sources, and the mechanism that we have uncovered here is likely to at least extend to these additional contexts. For example, AKAP79 underlies $G_{A B A}$ receptor regulation during LTD of GABAergic synapses (Dacher et alo, 2013), and it positions PKA and CN for regulation of TRPV channels (Zhang et al., 2008), Kv7 channels (Zhang and Shapiro, 2012), and $\beta$-adrenergic receptors (Houslay and Baillie, 2005). AKAP79 is also necessary for NFAT dephosphorylation following $\mathrm{Ca}^{2+}$ entry through both L-type calcium channels (Wild et al., 2019) and the store-operated $\mathrm{Ca}^{2+}$ channel ORAl1 (Kar et al., 2014). The RII IS phosphorylation site is conserved throughout the animal kingdom, and co-anchoring of phosphatases alongside PKA is a feature of several AKAP complexes (Redden and DodgeKafka, 2011). Future investigations may therefore explore whether additional anchoring proteins are able to direct $\mathrm{CN}$ - or other cellular phosphatases - for direct suppression of PKA activity. 


\section{Key resources table}

\section{Materials and methods}

\begin{tabular}{|c|c|c|c|c|}
\hline $\begin{array}{l}\text { Reagent type (species) } \\
\text { or resource }\end{array}$ & Designation & Source or reference & Identifiers & Additional information \\
\hline $\begin{array}{l}\text { Strain, strain } \\
\text { background (Escherichia } \\
\text { coli) }\end{array}$ & TOP10 chemically competent & Life Technologies & Cat\# C404003 & \\
\hline $\begin{array}{l}\text { Strain, strain } \\
\text { background (Escherichia } \\
\text { coli) }\end{array}$ & BL21 (DE3) & Thermo Fisher Scientific & Cat\# EC0114 & \\
\hline $\begin{array}{l}\text { Strain, strain } \\
\text { background (Escherichia } \\
\text { coli) }\end{array}$ & BL21 Tuner (DE3) pLysS & Merck & Cat\# 70,624 & \\
\hline $\begin{array}{l}\text { Strain, strain } \\
\text { background (Escherichia } \\
\text { coli) }\end{array}$ & BL21 Star (DE3) & Thermo Fisher Scientific & Cat\# C601003 & \\
\hline $\begin{array}{l}\text { Strain, strain } \\
\text { background (Escherichia } \\
\text { coli) }\end{array}$ & Stb/3 & Thermo Fisher Scientific & Cat\# C737303 & \\
\hline Cell line (Homo-sapiens) & HEK293 & Horizon Discovery LTD & Cat\# HCL3417 & Myocplasma tested. \\
\hline Cell line (Homo-sapiens) & HEK293T & ATCC & Cat\# CRL-3216 & Myocplasma tested. \\
\hline $\begin{array}{l}\text { Biological sample } \\
\text { (Rattus norvegicus) }\end{array}$ & Sprague Dawley & UCL breeding colony & Not applicable & \\
\hline Antibody & $\begin{array}{l}\text { (Mouse monoclonal) anti-PKA } \\
\text { RIl } \alpha\end{array}$ & BD Biosciences & Cat\# 612243; RRID:AB_399566 & $(0.8 \mu \mathrm{g} / \mathrm{mL})$ \\
\hline Antibody & $\begin{array}{l}\text { (Mouse monoclonal) anti-PKA } \\
\text { RII }\end{array}$ & BD Biosciences & Cat\# 610626; RRID:AB_397958 & $(0.8 \mu \mathrm{g} / \mathrm{mL})$ \\
\hline Antibody & $\begin{array}{l}\text { (Mouse monoclonal) anti-PKA C } \\
\text { (pan) }\end{array}$ & BD Biosciences & Cat\# 610981; RRID:AB_398294 & $(0.5 \mu \mathrm{g} / \mathrm{mL})$ \\
\hline Antibody & $\begin{array}{l}\text { (Mouse monoclonal) anti-PKA RI } \\
\text { (pan) }\end{array}$ & BD Biosciences & Cat\# 610166; RRID:AB_397567 & $(0.8 \mu \mathrm{g} / \mathrm{mL})$ \\
\hline Antibody & $\begin{array}{l}\text { (Rabbit monoclonal) anti-PKA } \\
\text { phospho-Rll } \alpha\end{array}$ & Abcam & Cat\# ab32390; RRID:AB_779040 & $(0.8 \mu \mathrm{g} / \mathrm{mL})$ \\
\hline Antibody & (Rabbit polyclonal) anti-GFP & Sigma Aldrich & $\begin{array}{l}\text { Cat\# SAB4301138; } \\
\text { RRID:AB_2750576 }\end{array}$ & $(0.5 \mu \mathrm{g} / \mathrm{mL})$ \\
\hline Antibody & $\begin{array}{l}\text { (Mouse monoclonal) anti- } \beta \text { - } \\
\text { tubulin }\end{array}$ & Biolegend & Cat\# 903401; RRID: AB_2565030 & $(0.5 \mu \mathrm{g} / \mathrm{mL})$ \\
\hline Antibody & $\begin{array}{l}\text { Goat anti-rabbit HRP-linked } \\
\text { secondary antibody }\end{array}$ & $\begin{array}{l}\text { Cell Signalling } \\
\text { Technology }\end{array}$ & Cat \# 7,074 S; RRID:AB_2099233 & $(1 \mu \mathrm{g} / \mathrm{mL})$ \\
\hline Antibody & $\begin{array}{l}\text { Goat anti-mouse lgG }(\mathrm{H}+\mathrm{L}) \\
\text { poly-HRP secondary antibody }\end{array}$ & Thermo Fisher Scientific & Cat\# 32230; RRID:AB_1965958 & $(1 \mu \mathrm{g} / \mathrm{mL})$ \\
\hline $\begin{array}{l}\text { Recombinant DNA } \\
\text { reagent }\end{array}$ & pIRES2-EGFP & Clontech & Cat\# 6029-1 & \\
\hline $\begin{array}{l}\text { Recombinant DNA } \\
\text { reagent }\end{array}$ & pFUGW-H1 & $\begin{array}{l}\text { Sally Temple lab/ } \\
\text { Addgene }\end{array}$ & $\begin{array}{l}\text { Cat\# 25870; } \\
\text { RRID:Addgene_25870 }\end{array}$ & Lentiviral entry vector. \\
\hline $\begin{array}{l}\text { Recombinant DNA } \\
\text { reagent }\end{array}$ & $\begin{array}{l}\text { pFUGW-shRII } \alpha-\text { RII } \alpha^{*} \text {-WT-IRES- } \\
\text { EGFP }\end{array}$ & This study & Not applicable & $\begin{array}{l}\text { Lentivral entry vector. } \\
\text { Dr. Matthew G. Gold } \\
\text { (University College London) }\end{array}$ \\
\hline $\begin{array}{l}\text { Recombinant DNA } \\
\text { reagent }\end{array}$ & $\begin{array}{l}\text { pFUGW-shRII } \alpha \text {-RII } \alpha{ }^{*} \text {-S97A- } \\
\text { IRES-EGFP }\end{array}$ & This study & Not applicable & $\begin{array}{l}\text { Lentivral entry vector. } \\
\text { Dr. Matthew G. Gold } \\
\text { (University College London) }\end{array}$ \\
\hline
\end{tabular}

Continued on next page 
Continued

\begin{tabular}{|c|c|c|c|c|}
\hline $\begin{array}{l}\text { Reagent type (species) } \\
\text { or resource }\end{array}$ & Designation & Source or reference & Identifiers & Additional information \\
\hline $\begin{array}{l}\text { Recombinant DNA } \\
\text { reagent }\end{array}$ & $\begin{array}{l}\text { pFUGW-shRII } \alpha-\text { RII } \alpha * \text {-S97E- } \\
\text { IRES-EGFP }\end{array}$ & This study & Not applicable & $\begin{array}{l}\text { Lentivral entry vector. } \\
\text { Dr. Matthew G. Gold } \\
\text { (University College London) }\end{array}$ \\
\hline $\begin{array}{l}\text { Recombinant DNA } \\
\text { reagent }\end{array}$ & pCMVdR8.74 \& pMD2.G plasmids & $\begin{array}{l}\text { Didier Trono lab/ } \\
\text { Addgene }\end{array}$ & $\begin{array}{l}\text { Cat\# 12259; } \\
\text { RRID:Addgene_12259 }\end{array}$ & Lentiviral packaging vectors \\
\hline $\begin{array}{l}\text { Recombinant DNA } \\
\text { reagent }\end{array}$ & pcDNA3.1-AKAR4-NES & Jin Zhang lab/Addgene & $\begin{array}{l}\text { Cat\# 64727; } \\
\text { RRID:Addgene_64727 }\end{array}$ & \\
\hline $\begin{array}{l}\text { Chemical compound, } \\
\text { drug }\end{array}$ & Lipofectamine 2000 & Thermo Fisher Scientific & Cat\# 11668019 & \\
\hline $\begin{array}{l}\text { Chemical compound, } \\
\text { drug }\end{array}$ & DMEM, high glucose, pyruvate & Thermo Fisher Scientific & Cat \# 41966029 & \\
\hline $\begin{array}{l}\text { Chemical compound, } \\
\text { drug }\end{array}$ & Trypsin & Thermo Fisher Scientific & Cat\# 25300054 & \\
\hline $\begin{array}{l}\text { Chemical compound, } \\
\text { drug }\end{array}$ & Penicillin/ Streptomycin & Thermo Fisher Scientific & Cat\# 15140122 & \\
\hline $\begin{array}{l}\text { Chemical compound, } \\
\text { drug }\end{array}$ & GlutaMAX & Thermo Fisher Scientific & Cat\# 35050061 & \\
\hline $\begin{array}{l}\text { Chemical compound, } \\
\text { drug }\end{array}$ & DPBS, no calcium, no magnesium & Thermo Fisher Scientific & Cat\# 14190144 & \\
\hline $\begin{array}{l}\text { Chemical compound, } \\
\text { drug }\end{array}$ & HBSS & Thermo Fisher Scientific & Cat\# 14185045 & \\
\hline $\begin{array}{l}\text { Chemical compound, } \\
\text { drug }\end{array}$ & Heat-inactivated horse serum & Gibco & Cat\# 26050088 & \\
\hline $\begin{array}{l}\text { Chemical compound, } \\
\text { drug }\end{array}$ & Neurobasal-A medium & Thermo Fisher Scientific & Cat\# 10888022 & \\
\hline $\begin{array}{l}\text { chemical compound, } \\
\text { drug }\end{array}$ & B27 supplement & Gibco & Cat\# 17504044 & \\
\hline $\begin{array}{l}\text { chemical compound, } \\
\text { drug }\end{array}$ & Poly-L-Lysine & Sigma Aldrich & Cat\# P2636 & \\
\hline $\begin{array}{l}\text { chemical compound, } \\
\text { drug }\end{array}$ & Boric acid & Sigma Aldrich & Cat\# B6768-500g & \\
\hline $\begin{array}{l}\text { chemical compound, } \\
\text { drug }\end{array}$ & Sodium tetraborate & Sigma Aldrich & Cat\# 221,732 & \\
\hline $\begin{array}{l}\text { chemical compound, } \\
\text { drug }\end{array}$ & $\begin{array}{l}\text { cOmplete, Mini, EDTA-free } \\
\text { Protease Inhibitor Cocktail }\end{array}$ & Roche & Cat\# 11836170001 & \\
\hline $\begin{array}{l}\text { chemical compound, } \\
\text { drug }\end{array}$ & $\begin{array}{l}\text { PhosSTOP phosphatase inhibitor } \\
\text { tablets }\end{array}$ & Roche & Cat\# 4906845001 & \\
\hline $\begin{array}{l}\text { chemical compound, } \\
\text { drug }\end{array}$ & Para-nitrophenylphosphate & Sigma Aldrich & Cat\# N3254 & \\
\hline software, algorithm & Origin & OriginLab & $\begin{array}{l}\text { http://www.originlab.com/; } \\
\text { RRID:SCR_014212 }\end{array}$ & \\
\hline software, algorithm & $\begin{array}{l}\text { Reader Control Software for } \\
\text { FLUOStar Omega }\end{array}$ & BMG Labtech & $\begin{array}{l}\text { https://www.bmglabtech.com } \\
\text { /reader-control-software/ }\end{array}$ & \\
\hline software, algorithm & MARS Data Analysis Software & BMG Labtech & $\begin{array}{l}\text { https://www.bmglabtech.com/ } \\
\text { mars-data-analysis-software/ }\end{array}$ & \\
\hline software, algorithm & $\begin{array}{l}\text { Unicorn Start } 1.1 \text { Software for } \\
\text { controlling AKTA start system }\end{array}$ & GE Healthcare & Cat\# 29225049 & \\
\hline software, algorithm & ImageJ (version 1.52) & $\mathrm{NIH}$ & RRID:SCR_003070 & \\
\hline software, algorithm & NeuronStudio & Rodriguez et al., 2008 & $\begin{array}{l}\text { https://icahn.mssm.edu; } \\
\text { RRID:SCR_013798 }\end{array}$ & \\
\hline
\end{tabular}




\section{Protein Expression and Purification}

Human PKA subunits were expressed and purified as described previously (Walker-Gray et al., 2017). GST-RIl $\alpha$ and GST-RII $\beta$ were expressed in Escherichia coli BL21 Tuner (DE3) pLysS, and GST-C $\beta$ in E. coli BL21 (DE3) grown in LB. In all cases, protein expression was induced by addition of $0.5 \mathrm{mM}$ isopropyl $\beta$-D-1-thiogalactopyranoside (IPTG), and bacteria were harvested following overnight incubation at $20{ }^{\circ} \mathrm{C}$. Cell pellets were thawed and sonicated in glutathione sepharose binding buffer ( $20 \mathrm{mM}$ HEPES $\mathrm{pH} 7.5,500 \mathrm{mM} \mathrm{NaCl}, 1 \mathrm{mM} \mathrm{DTT}, 0.5 \mathrm{mM}$ EDTA, $1 \mathrm{mM}$ benzamidine, 10 \% glycerol) supplemented with $0.1 \mathrm{mg} / \mathrm{mL}$ lysozyme, and $0.1 \%$ Igepal CA-630 (RIl subunit preps only). Clarified lysates were incubated with glutathione sepharose 4B, and PKA subunits were eluted by overnight cleavage with PreScission protease thus removing N-terminal GST affinity tags. Finally, each subunit was purified using a HiLoad 16/600 Superdex 200 column connected in series with a GSTrap to remove residual GST using gel filtration buffer (20 mM HEPES pH 7.5, $150 \mathrm{mM} \mathrm{NaCl}, 5 \%$ glycerol). S98A and S98E point mutations were introduced into Rlla subunits by site-directed mutagenesis (SDM) with primer pairs hS98A_F \& R, and hS98E_F \& R. Rlla variants were expressed and purified in the same way as the WT sequences.

Full-length human AKAP79 was cloned into pET28 using primers Nde1_AKAP79_1 and AKAP79_427_EcoRI for expression of N-terminally 6His-tagged protein. AKAP79 was expressed in $4 \mathrm{~L}$ BL21 Star (DE3) cells by overnight incubation at $37^{\circ} \mathrm{C}$ in auto-induction media (AIM). PBS-washed bacterial pellets were resuspended in Talon binding buffer $(30 \mathrm{mM}$ Tris pH 8.0, $500 \mathrm{mM} \mathrm{NaCl}, 10 \mathrm{mM}$ imidazole, $1 \mathrm{mM}$ benzamidine) supplemented with $0.1 \mathrm{mg} / \mathrm{mL}$ lysozyme and one Complete EDTA-free protease inhibitor tablet (Roche) per $100 \mathrm{~mL}$. Lysates were sonicated, clarified by centrifugation, and incubated with Talon Superflow resin for 2 hours prior to $3 \times 10 \mathrm{~mL}$ washing in Talon binding buffer, and eluted with $2 \times 2.5 \mathrm{~mL}$ Talon elution buffer $(30 \mathrm{mM}$ Tris, $\mathrm{pH} 7.0,500 \mathrm{mM} \mathrm{NaCl}, 300 \mathrm{mM}$ imidazole, $1 \mathrm{mM}$ benzamidine). Eluted protein was exchanged into Q buffer A ( $20 \mathrm{mM}$ Tris pH $8,20 \mathrm{mM} \mathrm{NaCl}$, $1 \mathrm{mM}$ EDTA, $2 \mathrm{mM}$ DTT) using a HiPrep 26/10 desalting column to enable purification using a $1 \mathrm{~mL}$ Resource $\mathrm{Q}$ column. Each variant was eluted using a $\mathrm{NaCl} / \mathrm{pH}$ gradient with $\mathrm{Q}$ buffer $\mathrm{A}$ and a steadily increasing proportion of $\mathrm{Q}$ buffer $\mathrm{B}(20 \mathrm{mM}$ Tris $\mathrm{pH}$ 7, $500 \mathrm{mM} \mathrm{NaCl}, 1 \mathrm{mM}$ EDTA, $2 \mathrm{mM}$ DTT). In the final step, peak fractions were pooled and buffer exchanged into gel filtration buffer. Residues 331-427 of AKAP79 were cloned into pET28 using primers Nde1_AKAP79_331 and AKAP79_427_ EcoRl for expression of the fragment AKAP79 ${ }_{977}$ bearing an $\mathrm{N}$-terminal His tag. This construct was transformed into BL21 (DE3) cells, which were grown overnight at $37^{\circ} \mathrm{C}$ in AIM. Lysis and metal affinity steps were as for full-length AKAP79 with the exception that Ni-NTA agarose (Life Technologies) was used in place of Talon resin. Following elution from Ni-NTA resin, the protein was purified by size exclusion using a HiLoad $16 / 600$ Superdex 200 pre-equilibrated in gel filtration buffer. To assemble complexes of full-length RII subunits and AKAP79 ${ }_{\mathrm{C} 97}$, mixtures of the purified proteins were incubated on ice in gel filtration buffer for $1 \mathrm{~h}$ with the AKAP fragment in a 2:1 molar excess. The complex was then separated from excess AKAP79 ${ }_{c 97}$ by Superdex 200 size exclusion. pET28-AKAP79 ${ }_{c 97} \triangle C N$ was generated by performing PCR with an earlier construct lacking residues 337-343 as the template (Gold et al., 2011), whereas the $\triangle P K A$ variant (lacking residues 391-400) was generated by SDM with primers $\triangle P K A \_F \& \_R$. The two AKAP79 ${ }_{c 97}$ deletion mutants were expressed and purified in the same way as the WT protein.

Human CN was expressed from a bicistronic pGEX6P1 vector (Gold et al., 2011) in E. coli BL21 Tuner (DE3) pLysS cells. Protein expression was induced by overnight incubation at $37^{\circ} \mathrm{C}$ in $4 \mathrm{~L}$ AIM. CN was purified following the same protocol as full-length PKA Rll subunits, with the final size exclusion step performed using gel filtration buffer supplemented with $1 \mathrm{mM}$ DTT. Human CaM was expressed and purified as described previously (Patel et al., 2017). Briefly, untagged CaM was expressed in E. coli BL21 (DE3) cells incubated overnight at $37{ }^{\circ} \mathrm{C}$ in AIM. CaM was initially purified using phenyl sepharose resin, then by ion exchange with a HiTrap Q HP column. Finally, CaM was exchanged into water and lyophilized prior to storage at $-80^{\circ} \mathrm{C}$. Human PP1 $\alpha$ (7-300) was expressed in BL21 (DE3) E. coli in LB media supplemented with $1 \mathrm{mM} \mathrm{MnCl} 2$ and purified as described previously (Kelker et alo, 2009). The PP1 expression vector was a gift from Wolfgang Peti (Addgene plasmid \# 26566). This vector was co-transformed with pGRO7 plasmid encoding the GroEL/GroES chaperone (Takara). PP1 expression was induced with $0.1 \mathrm{mM}$ IPTG after prior induction of chaperone expression using $2 \mathrm{~g} / \mathrm{L}$ arabinose. Bacteria were incubated for 20 hours at $10{ }^{\circ} \mathrm{C}$ following IPTG induction before harvesting. PP1 was purified by affinity to Ni-NTA agarose (Qiagen) followed by size exclusion with a Superdex 200 column equilibrated in PP1 gel filtration buffer (25 mM HEPES pH 7.5, $500 \mathrm{mM} \mathrm{NaCl}, 1 \mathrm{mM} \mathrm{MnCl}, 10 \%$ glycerol). For 
AKAR4 purification, an 8His epitope tag was ligated into pcDNA3.1-AKAR4-NES vector (Depry et al., 2011) (Addgene cat no. 64727) at the C-terminus of the sensor immediately prior to the nuclear export site using primers Ecol_8HisNLS_Xbal and Xbal_8HisNLS_EcoRI. The vector was transfected into $20 \times$ $10 \mathrm{~cm}$ dishes of HEK293T cells cultured in DMEM using lipofectamine-2000 (Thermo Fisher Scientific). Cells were collected after 3 days, washed in PBS, then lysed in Talon binding buffer supplemented with $0.5 \%$ lgepal CA-630, and sonicated briefly. AKAR4 was purified by affinity to Ni-NTA agarose following the same procedure as for AKAP79, and eluted protein was exchanged into gel filtration buffer, and aliquoted before storage at $-80^{\circ} \mathrm{C}$. All purification columns and resins were purchased from GE Healthcare. All protein samples were concentrated using Vivaspin centrifugal concentrators (Sartorius). Denaturing gel electrophoresis was performed using NuPAGE 4\%-12\% Bis-Tris gels (Thermo Fisher Scientific), and protein concentrations were determined using the bicinchoninic acid (BCA) assay. Oligonucleotide primer sequences are listed in Supplementary file 2.

\section{Phosphatase Assays}

For radioactive release assays, CN substrates were prepared by phosphorylating PKA RII subunits at the autoinhibitory site with PKA C subunit and $\operatorname{ATP}\left(\gamma^{-}{ }^{32} \mathrm{P}\right)$. To radiolabel RIl $\alpha$, RII $\beta$, or the purified complexes of each isoform with AKAP79 ${ }_{c 97}, 50 \mu \mathrm{g}$ of the relevant sample was incubated in $100 \mu \mathrm{L}$ with phosphorylation buffer (20 mM HEPES pH 7.5, $150 \mathrm{mM} \mathrm{NaCl}, 100 \mu \mathrm{M} \mathrm{cAMP}, 5 \mathrm{mM} \mathrm{MgCl}, 0.03 \mu \mathrm{g} / \mu \mathrm{L}$ $\mathrm{C}$ subunit) supplemented with $42 \mathrm{pmol}\left[{ }^{32} \mathrm{P}-\gamma\right]-A T P$ at $3,000 \mathrm{Ci} / \mathrm{mmol}$ and $10 \mu \mathrm{M}$ cold ATP. After $15 \mathrm{~min}$ incubation at $30{ }^{\circ} \mathrm{C}$, reactions were supplemented with $10 \mu \mathrm{M}$ additional cold ATP. Following 15 min further incubation, reactions were finally supplemented up to $1 \mathrm{mM}$ cold ATP for 10 min further incubation. ${ }^{32} \mathrm{P}$-labelled protein was immediately separated from free ${ }^{32} \mathrm{P}$ using Sephadex G-25 Medium equilibrated in phospho-substrate storage buffer $(20 \mathrm{mM} \mathrm{HEPES} \mathrm{pH} \mathrm{7.5,} 150 \mathrm{mM} \mathrm{NaCl}, 10 \%$ glycerol, $0.1 \mathrm{mM}$ EDTA). Additional cold phospho-labelled substrates were prepared using scaled-up reactions with $1 \mathrm{mM}$ cold ATP for $30 \mathrm{~min}$ at $30^{\circ} \mathrm{C}$.

Phosphatase assays using ${ }^{32} \mathrm{P}$-labelled substrate (final volume $50 \mu \mathrm{L}$ per assay) were prepared by first mixing appropriate dilutions of pRII substrates and CN on ice in dilution buffer (25 mM Na HEPES $\mathrm{pH} 7.5,150 \mathrm{mM} \mathrm{NaCl})$ to a final volume of $35 \mu \mathrm{L} .10 \mu \mathrm{L}$ of reaction buffer $(25 \mathrm{mM} \mathrm{Na} \mathrm{HEPES} \mathrm{pH}$ 7.5, $150 \mathrm{mM} \mathrm{NaCl}, 25 \mathrm{mM} \mathrm{MgCl}$, $5 \mathrm{mM}$ DTT, $0.5 \mathrm{mg} / \mathrm{mL}$ BSA, $1 \mathrm{mM}$ EDTA) was then added before

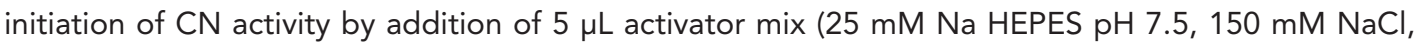
$\left.10 \mathrm{mM} \mathrm{CaCl}_{2}, 50 \mu \mathrm{M} \mathrm{CaM}\right)$. Assays was terminated after $30-60 \mathrm{~s}$ at $30{ }^{\circ} \mathrm{C}$ by addition of $350 \mu \mathrm{L} 30 \%$ trichloroacetic acid (TCA). Samples were then incubated on ice for $1 \mathrm{~h}$, and protein was pelleted by centrifugation at $21,360 \times \mathrm{g}$ for $15 \mathrm{~min}$ at $2{ }^{\circ} \mathrm{C}$. The separated supernatant and pellet were analyzed using a Beckman LS 6000SC scintillation counter to determine the fraction of phosphate released from the pRII substrate. Reaction conditions were optimized so that less than $10 \%$ pRII was dephosphorylated in each assay. Assays were generally performed with $10 \mathrm{nM} \mathrm{CN}$ and terminated after $30 \mathrm{~s}$, with the exception of measurements for $p R I l \alpha$ and pRII (black lines, Figure 1E \& F) where $60 \mathrm{~s}$ reactions containing $100 \mathrm{nM}$ CN were used.

For pNPP hydrolysis assays, para-nitrophenol (pNP) production was monitored continuously by measuring absorbance at $405 \mathrm{~nm}$ in a FLUOstar Omega microplate reader. Each $50 \mu \mathrm{L}$ assay contained $5 \mu \mathrm{L}$ of $10 \times \mathrm{pNPP}$ reaction buffer $(100 \mathrm{mM}$ Tris, $\mathrm{pH} 8.0,100 \mathrm{mM} \mathrm{NaCl}, 10 \mathrm{mM} \mathrm{CaCl} 2,1 \mathrm{mg} / \mathrm{ml}$ of BSA, $60 \mathrm{mM} \mathrm{MgCl} 2,10 \mathrm{mM}$ DTT), and $35 \mu \mathrm{L}$ solution containing proteins at the appropriate concentrations

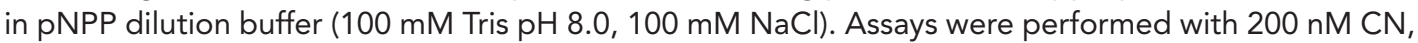
and $5 \mu \mathrm{M}$ CaM where appropriate. Reactions were initiated by addition of $10 \mu \mathrm{L} p N P P$ (Merck) to a final concentration of $5 \mathrm{mM}$, and pNP production was monitored at $22{ }^{\circ} \mathrm{C}$ for 1 hour at 1 minute intervals. For assays using phosphopeptide substrate, 19-mer pRII was synthesised by Biomatik at >95\% purity. Each $50 \mu \mathrm{L}$ assay contained $5 \mu \mathrm{L}$ of $10 \times$ phosphopeptide reaction buffer ( $25 \mathrm{mM}$ Na HEPES $\mathrm{pH}$ 7.5, $150 \mathrm{mM} \mathrm{NaCl}, 25 \mathrm{mM} \mathrm{MgCl}$, $5 \mathrm{mM}$ DTT, $0.5 \mathrm{mg} / \mathrm{mL}$ BSA, $1 \mathrm{mM}$ EDTA), and $30 \mu \mathrm{L}$ solution containing proteins at the appropriate concentrations in phosphopeptide dilution buffer $(25 \mathrm{mM} \mathrm{Na}$ HEPES pH 7.5, $150 \mathrm{mM} \mathrm{NaCl}$ ). Assays were performed with $100 \mathrm{nM} \mathrm{CN}$, and $3 \mu \mathrm{M}$ CaM where appropriate. Assays were initiated by addition of pRII phosphopeptide to a final concentration of $40 \mu \mathrm{M}$, and terminated by addition of $50 \mu \mathrm{L}$ Biomol Green solution (Enzo Life Sciences) following 3 min incubation at $22{ }^{\circ} \mathrm{C}$. Free phosphate concentration was determined by measuring absorbance at $624 \mathrm{~nm}$ in the FLUOstar Omega microplate reader. 


\section{Quantitative Immunoblotting of CA1 Neuropil Extracts}

Hippocampal slices were prepared from 18 day old male Sprague-Dawley rats. Rats were euthanized by cervical dislocation and $350 \mu \mathrm{m}$-thick hippocampal slices were collected using a Leica VT1200S microtome in ice-cold sucrose-based saline $(189 \mathrm{mM}$ sucrose, $10 \mathrm{mM}$ glucose, $3 \mathrm{mM} \mathrm{KCl}, 5 \mathrm{mM}$ $\mathrm{MgSO}_{4}, 26 \mathrm{mM} \mathrm{NaHCO}_{3}, 1.25 \mathrm{mM} \mathrm{NaH}_{2} \mathrm{PO}_{4}, 0.1 \mathrm{mM} \mathrm{CaCl}, \mathrm{pH} 7.4$ ) saturated with $95 \% \mathrm{O}_{2} / 5 \%$ $\mathrm{CO}_{2}$. Slices were next transferred to a storage chamber filled with artificial cerebrospinal fluid (aCSF; $124 \mathrm{mM} \mathrm{NaCl}, 3 \mathrm{mM} \mathrm{KCl}, 24 \mathrm{mM} \mathrm{NaHCO}, 1.25 \mathrm{mM} \mathrm{NaH}_{2} \mathrm{PO}_{4}, 1 \mathrm{mM} \mathrm{MgSO}$, $10 \mathrm{mM}$ glucose, 2 mM $\mathrm{CaCl}_{2}, \mathrm{pH} 7.4$ ) saturated with $95 \% \mathrm{O}_{2} / 5 \% \mathrm{CO}_{2}$ first for one hour at $\sim 31{ }^{\circ} \mathrm{C}$ and at room temperature thereafter. For micro-dissection, slices were transferred onto a pre-chilled Sylgard-coated $90 \mathrm{~mm}$ petri dish atop a dry ice/ethanol bath. The CA1 neuropil layer was micro-dissected using an angled micro-knife (Cajigas et al., 2012) by first cutting along the borders of the stratum pyramidale/stratum radiatum and the stratum lacunosum moleculare/hippocampal fissure. Subsequent lateral cuts at the CA2-CA1 and subiculum-CA1 borders completed the rectangular micro-slices. Micro-dissected neuropil slices were immediately snap frozen in liquid nitrogen and stored at $-80{ }^{\circ} \mathrm{C}$. To extract protein, neuropil slices ( 15 per animal) were first pulverized with a micro-pestle then resuspended in a final volume of $300 \mu \mathrm{L}$ extraction buffer $(50 \mathrm{mM}$ Tris- $\mathrm{HCl}, 50 \mathrm{mM} \mathrm{NaF}, 10 \mathrm{mM}$ EGTA, $10 \mathrm{mM}$ EDTA, $0.08 \mathrm{mM}$ sodium molybdate, $5 \mathrm{mM}$ sodium pyrophosphate, $1 \mathrm{mM}$ penylmethylsulfonyl fluoride, $0.5 \%$ $\mathrm{mM}$ Igepal CA-630, 0.25\% mM sodium deoxycholate, $4 \mathrm{mM}$ para-nitrophenylphosphate, cOmplete EDTA-free protease inhibitors and PhosStop phosphatase inhibitors (Roche) at one tablet each per $50 \mathrm{~mL}$ ). The homogenate was sonicated briefly $(30 \mathrm{~s}$ at $20 \mathrm{MHz}$ ) then clarified by centrifugation at $21,130 \times g\left(15 \mathrm{~min}\right.$ at $\left.4{ }^{\circ} \mathrm{C}\right)$. Total protein concentration in each extract was determined by BCA assay. Quantitative immunoblotting was performed as described previously (Walker-Gray et al., 2017) using anti-PKA subunit primary antibodies purchased from BD Biosciences. HRP-conjugated secondary antibodies were detected with WesternBright ECL chemiluminescent HRP substrate using a ImageQuant imaging unit (GE Healthcare). Band intensities for reference protein standards and neuropil extracts were calculated in ImageJ. For each immunoblot, a reference curve was generated by fitting reference protein concentrations and band intensities to a Hill function (with typical $R^{2}$ coefficients $>0.99$ ) using iterative least squares refinement with the Levenberg-Marquardt algorithm in Origin (OriginLab). PKA subunit concentrations in neuropil extracts were determined by cross-referencing to reference curves derived from the same immunoblot.

\section{AKAR4 Measurements}

AKAR4 fluorescence measurements were performed using black-walled 96-well plates in a FLUOstar Omega microplate reader (BMG Labtech) equipped with a $430 \mathrm{~nm}$ excitation filter, and $485 \mathrm{~nm} / 520 \mathrm{~nm}$ emission filters. Each $50 \mu \mathrm{L}$ reaction contained $35 \mu \mathrm{L}$ proteins mixed in dilution buffer (20 mM HEPES $\mathrm{pH} 7.5$ and $100 \mathrm{mM} \mathrm{NaCl})$ including AKAR4 reporter $(0.2 \mu \mathrm{M}$ final concentration in all cases) and $5 \mu \mathrm{L}$ of $10 x$ reaction buffer $(20 \mathrm{mM} \mathrm{Na}$ HEPES $\mathrm{pH}$ 7.5, $100 \mathrm{mM} \mathrm{NaCl}, 10 \mathrm{mM}$ DTT, $100 \mathrm{mM} \mathrm{MgCl}$, $10 \mathrm{mM} \mathrm{CaCl}_{2}, 0.5 \%$ Igepal CA-630). After three baseline measurements, PKA phosphorylation was initiated by addition of $10 \mu \mathrm{L}$ solution containing ATP and the desired concentration of cAMP using two injectors built into the plate reader. One injector was primed with ATP solution (20 mM Na HEPES $\mathrm{pH} 7.5,100 \mathrm{mM} \mathrm{NaCl}, 25 \mathrm{mM} \mathrm{ATP}$ ) and the other with ATP/cAMP solution (20 mM Na HEPES pH 7.5, $100 \mathrm{mM} \mathrm{NaCl}, 25 \mathrm{mM}$ ATP, 2.5 or $10 \mu \mathrm{M}$ cAMP) so that different proportions of the two injectors could be used to vary the final CAMP concentration. Measurements were collected at 5 second intervals for a minimum of 10 minutes at $22{ }^{\circ} \mathrm{C}$ following injection of ATP. For every run, one control well was included in which AKAR4 was omitted from the protein mixture to enable baseline subtraction.

Phosphorylated AKAR4 (pAKAR4), for use in assays comparing PP1 and CN activity towards the reporter, was prepared by incubating $400 \mu \mathrm{g}$ purified AKAR4 with $20 \mu \mathrm{g}$ PKA C subunit in $1 \mathrm{~mL}$ AKAR4 phosphorylation buffer (25 mM Na Hepes pH 7.5, $150 \mathrm{mM} \mathrm{NaCl}, 10 \mathrm{mM} \mathrm{MgCl}, 5 \mathrm{mM}$ ATP, $2 \mathrm{mM}$ DTT). Following $30 \mathrm{~min}$ incubation at $30^{\circ} \mathrm{C}$, the phosphorylated reporter was exchanged into $25 \mathrm{mM} \mathrm{Na}$ Hepes pH 7.5 and $100 \mathrm{mM} \mathrm{NaCl}$ using Sephadex G-25 medium. In pAKAR4 dephosphorylation assays, each well contained $35 \mu \mathrm{L}$ phosphatase at the appropriate concentration in dilution buffer mixed with $5 \mu \mathrm{L}$ of $10 \times$ reaction buffer. Reactions were initiated by injection of $10 \mu \mathrm{L}$ AKAR4 solution to a final concentration of $0.2 \mu \mathrm{M}$, and measurements were collected at $5 \mathrm{~s}$ intervals for 15 minutes thereafter. For all AKAR4 assays, run parameters were set using Reader Control Software 
for FLUOstar Omega, and measurements were analyzed using MARS Data Analysis Software (BMG Labtech). Aliquots of a single AKAR4 purification were used across all experiments.

\section{Kinetic Modeling}

The model scheme of PKA activation is an updated and extended version of the one published by Buxbaum and Dudai, 1989. The model was simulated in a single reaction compartment devoid of any geometry as a system of chemical reactions mimicking the experimental conditions listed above. The individual chemical reactions were modeled as ordinary differential equation (ODE) using the chemical mass-action equation, as:

$$
\begin{gathered}
\stackrel{k_{f}}{\mathrm{~A}+\mathrm{B} \Longleftrightarrow \mathrm{AB}} \\
k_{r} \\
\frac{-d[A]}{d t}=\frac{-d[B]}{d t}=\frac{d[A B]}{d t}=k_{f}(x)=k_{f}[A][B]=k_{r}[A B]
\end{gathered}
$$

In total, there were 16 chemical species and 16 reactions included in the model, incorporating mostly bi-molecular reactions with forward and backward reaction rates. Enzymatic reactions were represented by the three elementary steps of binding, dissociation and catalysis. All model variants were built using the MATLAB Simbiology toolbox (MathWorks). All reactions, along with initial concentrations of all chemical species and kinetic rates, are listed in Supplementary file 1.

PKA activation follows a sequential binding of four cAMP molecules to the PKA regulatory RII subunit holoenzyme followed by the release (or activation) of two active catalytic subunits (Taylor et al., 2019). However, the chosen modeling approach involved some simplifications: (1) The two RII subunits within the holoenzyme were assumed to behave independently - whereas in reality, some cooperativity is observed in PKA activation due to intra-dimeric contacts within the PKA holoenzymes (Zhang et al., 2012); (2) The two cAMP binding sites on the Rll subunit were modelled as a single binding event such that binding of cAMP to RII/pRII is first order with respect to cAMP (Hao et al., 2019). This simplification was incorporated as our focus here was on understanding transitions between pRII and RII subunits and not the precise mechanism of cAMP activation; (3) The respective dephosphorylation parameters for both pRII and pRII bound to cAMP were assumed to be equal; (4) Rates of RII phosphorylation by bound C subunit were assumed to be equal irrespective of whether cAMP was bound to the regulatory subunit; (5) RIl $\alpha$ and RII $\beta$ were assumed to behave similarly since isoform-specific differences were not the focus here. These simplifications were used to reduce the number of model parameters.

Parameters corresponding to the reactions involving dephosphorylation by $\mathrm{CN}$ were modified to represent the situations 'with' and 'without' AKAP79 (Supplementary file 1). In total eighteen different experimental AKAR4 responses were used to estimate the model parameters. Twelve corresponded to data shown in Figure $3 C$ \& E collected with either $0,0.2,1$ or $2 \mu \mathrm{M}$ cAMP activation: conditions with PKA (II)+ CaM either alone, with CN, or with both CN and AKAP79. The other six correspond to the calibration curves of $\mathrm{C}$ subunit interaction with AKAR4 (Figure 3-figure supplement 1A), which were used to estimate AKAR4 parameters that were kept frozen when the other model parameters were estimated. All parameters were estimated using an approximate Bayesian computation (ABC) approach, which included copulas for merging of different experimental data sets (Eriksson et al., 2019). A Bayesian approach was used over optimization for a single parameter set, to account for the uncertainty in the parameter estimates, and that more than one set of parameters could fit the data. The result is thus described using distributions for possible parameter values, rather than single values. Initial prior knowledge about the possible parameter values using data from this study, and previously published work from other groups (Buxbaum and Dudai, 1989; Isensee et al., 2018; Moore et al., 2003), was used to initiate the parameter fitting (details in Supplementary file 1). To account for parameter uncertainty, a log uniform prior distribution for the ABC-method was used. Many of the parameters were set to have a 'prior' range which varied three orders of magnitude from a default parameter value (black bar in Figure 5-figure supplement 1A), which ensured that different parameter values adopted in previous studies were included in the prior range. Simulations were started with initial conditions mimicking the experimental settings, thus for the WT system the initial conditions were assumed to reflect that all RII were either free or bound to $C$ with no phosphorylated species or interactions with cAMP. Simulations were then run for the same length 
as time as the experiments, assuming the cAMP was added at $\mathrm{t}=0$ and that autophosphorylation started at that time.

For predicting responses with mutant RIl $\alpha$ subunits, the base model was extended by splitting the RII into two pools, namely RIl $\alpha$ (85\%) and RII $\beta$ (15\%) but keeping the parameter distribution received from the parameter estimation when only one isoform of RII was accounted for. Experiments with WT RII subunits were successfully re-simulated with the extended model to validate the approach. As the mutations when simulating both S98A and S98E were in the Rlla subtype (85\%), the corresponding parameters depicting the mutation were only varied for this pool. Both the mutant forms, S98A and S98E, were tested as different model variants. To mimic the conditions of the S98A mutation in the model, the phosphorylation rates of RIl $\alpha$ and RIl $\alpha$ bound with cAMP were set to zero (i.e. for the RIl $\alpha$ partition of the model, kinetics were restricted to the right-hand square sub-system shown in Figure 4D). Here the initial conditions were estimated in the same way as described above. To mimic the S98E mutation in the model, the turnover number for dephosphorylation of $p R I l \alpha$ and $p R I l \alpha$ with cAMP by CN were set to zero (i.e. for the RIl $\alpha$ partition of the model, kinetics were restricted to the left-hand square in Figure 4D). Since S98E mimics a case where all the RIl subunits are phosphorylated, in this case initial conditions were such that all RIl $\alpha$ were distributed between $p R I / \alpha$ and $p R I / \alpha-C$.

All model variants were built using the MATLAB Simbiology toolbox (MathWorks). Simulations of these reaction systems were performed using the ode15s solver. All simulations were run for $605 \mathrm{~s}$ and the AKAR4 phosphorylation was extracted as output to compare with the experimental findings. The model equations were also exported to the statistical programming language R (https://www. r-project. org/) for implementing the parameter estimation through the ABC-copula approach (Eriksson et al., 2019) and only accept parameter sets whose simulated phosphorylated AKAR4 curves reproduced the experimental measurements. A slight modification to the distance measure $\rho$ was introduced to include timeseries data, where $\rho=\left(\sum_{i}\left(y_{i}^{e x p}-y_{i}^{\operatorname{sim}}\right)^{2}\right) / n$ where y are experimental and simulated data points (normalized to be within 0 and 1 ) and $n$ the number of data points for the experiment (for details see the code repository). The sampling resulted in approximately 15,000 parameter samples (a subset of which are shown in Figure 5-figure supplement 1A) which all fitted the experimental data within a threshold set to $\rho<0.01$. All parameter set samples, describing the uncertainty in the parameter estimates, were next projected onto the situations with mutant RIl $\alpha$ subunits. The model immediately reproduced the experimental observations with Rll $\alpha$ S98E subunits. Although the model correctly reproduced lower rates of AKAR4 that occur with RIl $\alpha$ S98A subunits, and that suppression of PKA activity by AKAP79/CN is reduced in this case, there was a substantial spread in the simulated responses in this case. This indicated that WT data had not perfectly constrained the dynamics in the unphosphorylated RII sub-system (right-hand square, Figure 4B). Therefore, to better understand which parameter characteristics that were important to also account for the RIl $\alpha$ S98A, the parameter sets were sub-classified based on how well they fit mutation data (Figure 5B-D) using a threshold of 0.01. The parameter sets and its effect on different chemical species of the model were described by multi- trajectory, pairwise coordinate and boxplots, where the color schemes follow the classification described above. A code repository for this study may be accessed at https://github.com/jdgas/ AKAP79_PKA (copy archived at swh:1:rev:0fb83d341f568ac92340857be7886b3ccc3004b3, Eriksson, 2021). It contains the $R$ code for the $A B C$ method as well as MATLAB code for reproducing figures. The $\mathrm{R}$ code has to be run on a computer cluster. The repository also contains the models with a few example parameter sets and the full parameter sample as described above.

\section{Lentivirus Construction}

Lentiviruses were generated by inserting RIl $\alpha$-IRES2-GFP expression cassettes into a pFUGW-H1 lentiviral vector (Addgene cat no. 25870) containing a shRNA sequence targeting for rat RIl $\alpha$. In the first step, coding sequence for rat PKA RIl $\alpha$ was isolated from a cDNA library that we generated from total hippocampal RNA from a 7 day old male Sprague Dawley rat bred in the UCL colony. RNA was extracted using an RNeasy Mini Kit before the cDNA library was generated using the first-strand cDNA synthesis kit. Coding sequence for Rll $\alpha$ was amplified from the library using primers Prkar2a_F \& Prkar2a_R and inserted upstream of the IRES2 sequence in pIRES2-GFP (Clontech) using EcoRI and $\mathrm{BamHI}$ entry sites. Three pFUGW-H1-shRIl $\alpha$ vectors were constructed to determine an optimal targeting sequence for knockdown of rat RIl $\alpha$. The targeting sequences (primer pairs shRIl $\alpha$ F1/R1, shRIla_F2/R2, and shRIla_F3/R3) were inserted using the Xbal site of pFUGW-H1. The efficiency of 
each targeting sequence was determined by co-transfecting HEK293T cells with pIRES2-RIl $\alpha$-EGFP and each pFUGW-H1 vector, with the pFUGW vector in a 10-fold excess. Anti-RIl $\alpha$ immunoblotting revealed that sequence shRIl $\alpha-1$, which targets bases 134-154 in the rat Rll $\alpha$ coding sequence, was particularly effective at knocking down RIl $\alpha$ protein levels (Figure 6B) so this variant served as the parent pFUGW-H1-shRIl $\alpha$ vector in the subsequent steps. The coding sequence for RIl $\alpha$ in pIRES2RIl $\alpha$-GFP was rendered shRNA-resistant ('RIl $\alpha^{\star^{\prime}}$ ) by SDM with primers Prkar2a_shRNA_resist_F \& R. After introducing an Nhel entry site into pFUGW-H1-shRIl $\alpha$ by SDM using primers FUGW_Nhel_F \& R, the dual expression cassette for RIl $\alpha$-IRES2-GFP was transferred across into pFUGW-H1-shRIl $\alpha$ downstream of the ubiquitin promoter using Nhel and Agel sites to create the complete lentiviral vector pFUGW-H1-shRIl $\alpha$-RIl $\alpha^{*}$-IRES2-EGFP.

Vectors containing RIl $\alpha$ replacement sequences with mutations at S97 were obtained by SDM with primers pairs rS97A_F \& R and rS97E_F \& R. In addition, a control vector containing a scrambled shRNA sequence was constructed using primers shScram_F \& R. To produce lentivirus, pFUGW vectors were co-transfected with pCMVdR8.74 packaging vector (Addgene cat no. 12259) and pMD2.G envelope glycoprotein vector (Addgene cat no. 12259) into HEK293 cells using Lipofectamine 2000 and maintained in DMEM supplemented with $10 \%$ FBS. Cell culture media was collected at both 48 and 72 hours after transfection, subjected to $0.45 \mu \mathrm{m}$ filtering, and centrifuged at $48,384 \times g$ for 4 hours at $4{ }^{\circ} \mathrm{C}$ to concentrate viral particles. Pelleted virus was resuspended in sterile PBS and stored at $-80^{\circ} \mathrm{C}$. Lentiviruses were validated by transducing dissociated hippocampal cultures on DIV7. Neurons were collected on DIV14, and protein extracted using sonication $(3 \times 10 \mathrm{~s}$ at $20 \mathrm{MHz})$ in extraction buffer. The homogenate was clarified by centrifugation at 21,130 x g for 15 minutes before analysis of protein levels in the supernatant by immunoblotting using antibodies including anti-PKA pRIl $\alpha$ (Abcam, RRID: AB_779040), anti-GFP (Sigma Aldrich, RRID: AB_2750576), and anti- $\beta$-tubulin antibodies (Biolegend, RRID: AB_2565030).

\section{Lentiviral Infection and Imaging of Dissociated Primary Hippocampal Neurons}

Primary hippocampal cultures were cultured from E18 Sprague-Dawley pups. Hippocampi were isolated and triturated with trypsin $(0.025 \%)$ before plating on poly-L-lysine-coated coverslips or 6-well plates in DMEM containing $10 \%$ heat-inactivated horse serum, and penicillin $(40 \mathrm{U} / \mathrm{mL}) / \mathrm{strep}$ tomycin $(40 \mu \mathrm{g} / \mathrm{mL})$. Neurons were cultured at $37^{\circ} \mathrm{C}$ in $95 \%$ air $/ 5 \% \mathrm{CO}_{2}$. Two hours after seeding, the plating media was replaced with Neurobasal-A supplemented with $1 \%$ B27, $0.5 \%$ (v/v) GlutaMAX, $20 \mathrm{mM}$ glucose, and penicillin $(100 \mathrm{U} / \mathrm{mL}) /$ streptomycin $(100 \mu \mathrm{g} / \mathrm{mL})$. Culture media and additives were purchased from Gibco with the exception of GlutaMAX (Thermo Fisher Scientific). Neurons were infected with lentivirus at DIV7 or DIV9 for dendritic spine density and time-lapse experiments, respectively. Concentrated viral stocks were diluted in conditioned media and incubated with neurons for 18 hours before replacing with fresh pre-conditioned media. Live-cell confocal imaging of dendritic spines was performed using an upright Zeiss LSM 510 confocal microscope equipped with an Achroplan $40 \times$ water differential interference contrast objective (numerical aperture 0.8). Transduced neurons were washed four times in HEPES-buffered Krebs solution $(140 \mathrm{mM} \mathrm{NaCl}, 4.2 \mathrm{mM}$ $\mathrm{KCl}, 1.2 \mathrm{mM} \mathrm{MgCl} 2,2.52 \mathrm{mM} \mathrm{CaCl}, 5 \mathrm{mM} \mathrm{Na}$ HEPES , and $11 \mathrm{mM}$ glucose, adjusted to $\mathrm{pH} 7.4$ with $\mathrm{NaOH}$ ) and placed into a chamber in this same solution at room temperature. For each dendritic segment, upper and lower bounds in the z-plane were initially determined using a rapid z-scan. A full image stack was then collected using a $488 \mathrm{~nm}$ Argon laser and a $505-530 \mathrm{~nm}$ band-pass emission filter for imaging EGFP fluorescence using $512 \times 512$ frames with 3 -line averaging, and optical slice spacing of $1.035 \mu \mathrm{m}$. Time-lapse experiments were conducted to measure changes in spine density and spine-head size after the induction of chemical LTD. An optical slice spacing of $0.9 \mu \mathrm{m}$ was used during time-lapse experiments. Z-stacks were acquired every $5 \mathrm{~min}$ from $15 \mathrm{~min}$ before to $60 \mathrm{~min}$ after the induction of chemical LTD. Bath application of $20 \mu \mathrm{M}$ NMDA for 3 min was used to induce NMDAR-dependent LTD (Lee et al., 1998). Data was deconvolved using ImageJ (NIH) before automated dendrite identification and classification in NeuronStudio (Rodriguez et al., 2008). In timelapse experiments, dendritic spine densities were normalized to the value at $t=0$. 


\section{Statistical analysis}

All data are presented as means \pm SE. Kinetic rates were statistically compared using two-tailed unpaired Student $t$-tests. Spine imaging data was compared by ANOVA with Turkey post-hoc tests (Figure 6D) and Bonferroni's post-hoc test (Figure 6G). ${ }^{\star} P<0.05 ;{ }^{\star \star} P<0.01$; ${ }^{\star \star \star} P<0.001$.

\section{Acknowledgements}

We thank Denis Yuan for assistance with protein purification, and Alexandra Jauhiainen, Andrei Kramer and Federica Milinanni for help with the parameter estimation process. MGG is a Wellcome Trust and Royal Society Sir Henry Dale fellow (104194/Z/14 /A), and is grateful for support from the BBSRC (BB/ N015274/1). SH is a Rett Syndrome Fellow and also supported by a Wellcome Trust Collaborative award to TGS. The research was supported by the Swedish Research Council (VR-M-2017-02806; VR-M-2020-01652), the Swedish e-Science Research Centre (SeRC), European Union/Horizon 2020 no. 945,539 Human Brain Project SGA3, and an Erasmus Scholarship from Portugal. Optimizations and simulations were performed on resources provided by the Swedish National Infrastructure for Computing (SNIC) at Lunarc, Lund University.

\section{Additional information}

Funding

\begin{tabular}{|c|c|c|}
\hline Funder & Grant reference number & Author \\
\hline Wellcome Trust & 104194/Z/14/A & Matthew G Gold \\
\hline Royal Society & 104194/Z/14/A & Matthew G Gold \\
\hline $\begin{array}{l}\text { Biotechnology and } \\
\text { Biological Sciences } \\
\text { Research Council }\end{array}$ & BB/N015274/1 & Matthew G Gold \\
\hline Swedish Research Council & VR-M-2017-02806 & $\begin{array}{l}\text { Jeanette Hellgren } \\
\text { Kotaleski }\end{array}$ \\
\hline Horizon 2020 & $\begin{array}{l}945539 \text { Human Brain } \\
\text { Project SGA3 }\end{array}$ & $\begin{array}{l}\text { Jeanette Hellgren } \\
\text { Kotaleski }\end{array}$ \\
\hline Erasmus+ & Erasmus Scholarship & João Antunes \\
\hline Wellcome Trust & 217199/Z/19/Z & $\begin{array}{l}\text { Saad Hannan } \\
\text { Trevor G Smart }\end{array}$ \\
\hline Swedish Research Council & VR-M-2020-01652 & $\begin{array}{l}\text { Jeanette Hellgren } \\
\text { Kotaleski }\end{array}$ \\
\hline $\begin{array}{l}\text { Swedish e-Science } \\
\text { Research Centre (SeRC) }\end{array}$ & & $\begin{array}{l}\text { Olivia Eriksson } \\
\text { Jeanette Hellgren } \\
\text { Kotaleski }\end{array}$ \\
\hline
\end{tabular}

The funders had no role in study design, data collection and interpretation, or the decision to submit the work for publication.

Author contributions

Timothy W Church, Conceptualization, Funding acquisition, Investigation, Supervision, Visualization, Writing - original draft, Writing - review and editing; Parul Tewatia, Investigation, Software, Visualization, Writing - original draft, Writing - review and editing; Saad Hannan, João Antunes, Olivia Eriksson, Investigation, Software, Visualization, Writing - review and editing; Trevor G Smart, Jeanette Hellgren Kotaleski, Funding acquisition, Investigation, Software, Supervision, Visualization, Writing review and editing; Matthew G Gold, Conceptualization, Funding acquisition, Investigation, Software, Supervision, Visualization, Writing - original draft, Writing - review and editing

Author ORCIDs

Timothy W Church (iD http://orcid.org/0000-0002-5958-6304

Parul Tewatia (iD http://orcid.org/0000-0002-3096-1318 
Saad Hannan (iD http://orcid.org/0000-0003-4594-0808

João Antunes (iD) http://orcid.org/0000-0001-9635-5145

Olivia Eriksson (DiD http://orcid.org/0000-0003-0740-4318

Trevor G Smart (iD http://orcid.org/0000-0002-9089-5375

Jeanette Hellgren Kotaleski (D) http://orcid.org/0000-0002-0550-0739

Matthew G Gold (iD http://orcid.org/0000-0002-1281-0815

Ethics

Experiments involving rats were done in accordance with the United Kingdom Animals Act, 1986 and within University College London Animal Research guidelines overseen by the UCL Animal Welfare and Ethical Review Body under project code 14058.

Decision letter and Author response

Decision letter https://doi.org/10.7554/eLife.68164.sa1

Author response https://doi.org/10.7554/eLife.68164.sa2

\section{Additional files}

Supplementary files

- Supplementary file 1. Kinetic modeling parameters. The table lists parameters used in the computational modeling. Parameter terminology is according to the numbers above stated in Figure 4D, for example $k 12$ refers to the on rate of cAMP binding to state 1 (pRII-C) to produce state 2 ( $p R I I-C-c A M P$ ). The prior range used to constrain parameter estimation is provided for each parameter along with links to the references used to set the default values.

- Supplementary file 2. Oligonucleotide primer sequences.

- Transparent reporting form

- Source data 1. Original images of Coomassie-stained gels and immunoblots included in the manuscript.

Data availability

Source data files have been provided for figures 1-6, figure 1-supplement 2, figure 1-supplement 3, figure 3-supplement 1, and figure 3-supplement 2. Original images and uncropped images for Coomassie-stained gels and immunoblots presented in the manuscript are shown in the zipped folder provided as an additional file. A code repository for this study may be accessed at https://github. com/jdgas/AKAP79_PKA, (copy archived swh:1:rev:0fb83d341f568ac92340857be7886b3ccc3004b3). It contains the $R$ code for the $A B C$ method as well as MATLAB code for reproducing figures. The $R$ code has to be run on a computer cluster. The repository also contains the models with a few example parameter sets, and the full parameter sample as described above.

\section{References}

Aye TT, Scholten A, Taouatas N, Varro A, Van Veen TAB, Vos MA, Heck AJR. 2010. Proteome-wide protein concentrations in the human heart. Molecular BioSystems 6: 1917-1927. DOI: https://doi.org/10.1039/ c004495d, PMID: 20596566

Baillie GS, Tejeda GS, Kelly MP. 2019. Therapeutic targeting of 3', $5^{\prime}$-cyclic nucleotide phosphodiesterases: inhibition and beyond. Nature Reviews. Drug Discovery 18: 770-796. DOI: https://doi.org/10.1038/s41573019-0033-4, PMID: 31388135

Baldwin TA, Dessauer CW. 2018. Function of Adenylyl Cyclase in Heart: the AKAP Connection. Journal of Cardiovascular Development and Disease 5: E2. DOI: https://doi.org/10.3390/jcdd5010002, PMID: 29367580

Bear MF. 2003. Bidirectional synaptic plasticity: from theory to reality. Philosophical Transactions of the Royal Society of London. Series B, Biological Sciences 358: 649-655. DOI: https://doi.org/10.1098/rstb.2002.1255, PMID: 12740110

Bers DM, Xiang YK, Zaccolo M. 2019. Whole-Cell cAMP and PKA Activity are Epiphenomena, Nanodomain Signaling Matters. Physiology 34: 240-249. DOI: https://doi.org/10.1152/physiol.00002.2019, PMID: 31165682

Blumenthal DK, Takio K, Hansen RS, Krebs EG. 1986. Dephosphorylation of cAMP-dependent protein kinase regulatory subunit (type II) by calmodulin-dependent protein phosphatase. Determinants of substrate specificity. The Journal of Biological Chemistry 261: 8140-8145 PMID: 3013843. ,

Bock A, Annibale P, Konrad C, Hannawacker A, Anton SE, Maiellaro I, Zabel U, Sivaramakrishnan S, Falcke M, Lohse MJ. 2020. Optical Mapping of cAMP Signaling at the Nanometer Scale. Cell 182: 1519-1530. DOI: https://doi.org/10.1016/j.cell.2020.07.035, PMID: 32846156 
Buxbaum JD, Dudai Y. 1989. A quantitative model for the kinetics of cAMP-dependent protein kinase (type II) activity. Long-term activation of the kinase and its possible relevance to learning and memory. The Journal of Biological Chemistry 264: 9344-9351 PMID: 2722837.,

Cajigas IJ, Tushev G, Will TJ, tom Dieck S, Fuerst N, Schuman EM. 2012. The local transcriptome in the synaptic neuropil revealed by deep sequencing and high-resolution imaging. Neuron 74: 453-466. DOI: https://doi.org/ 10.1016/j.neuron.2012.02.036, PMID: 22578497

Clouet DH, Gaitonde MK. 1956. The changes with age in the protein composition of the rat brain. Journal of Neurochemistry 1: 126-133. DOI: https://doi.org/10.1111/j.1471-4159.1956.tb12063.x, PMID: 13398827

Coghlan VM, Perrino BA, Howard M, Langeberg LK, Hicks JB, Gallatin WM, Scott JD. 1995. Association of protein kinase $A$ and protein phosphatase 2B with a common anchoring protein. Science 267: 108-111. DOI: https://doi.org/10.1126/science.7528941, PMID: 7528941

Dacher M, Gouty S, Dash S, Cox BM, Nugent FS. 2013. A-kinase anchoring protein-calcineurin signaling in long-term depression of GABAergic synapses. The Journal of Neuroscience 33: 2650-2660. DOI: https://doi. org/10.1523/JNEUROSCI.2037-12.2013, PMID: 23392692

Delint-Ramirez I, Willoughby D, Hammond GRV, Hammond GVR, Ayling LJ, Cooper DMF. 2011. Palmitoylation targets AKAP79 protein to lipid rafts and promotes its regulation of calcium-sensitive adenylyl cyclase type 8. The Journal of Biological Chemistry 286: 32962-32975. DOI: https://doi.org/10.1074/jbc.M111.243899, PMID: 21771783

Dell'Acqua ML, Faux MC, Thorburn J, Thorburn A, Scott JD. 1998. Membrane-targeting sequences on AKAP79 bind phosphatidylinositol-4, 5-bisphosphate. The EMBO Journal 17: 2246-2260. DOI: https://doi.org/10.1093/ emboj/17.8.2246, PMID: 9545238

Dell'Acqua ML, Dodge KL, Tavalin SJ, Scott JD. 2002. Mapping the protein phosphatase-2B anchoring site on AKAP79. Binding and inhibition of phosphatase activity are mediated by residues 315-360. The Journal of Biological Chemistry 277: 48796-48802. DOI: https://doi.org/10.1074/jbc.M207833200, PMID: 12354762

Depry C, Allen MD, Zhang J. 2011. Visualization of PKA activity in plasma membrane microdomains. Molecular BioSystems 7: 52-58. DOI: https://doi.org/10.1039/c0mb00079e, PMID: 20838685

Dittmer PJ, Dell'Acqua ML, Sather WA. 2014. Ca2+/calcineurin-dependent inactivation of neuronal L-type Ca2+ channels requires priming by AKAP-anchored protein kinase A. Cell Reports 7: 1410-1416. DOI: https://doi. org/10.1016/j.celrep.2014.04.039, PMID: 24835998

Eriksson O, Jauhiainen A, Maad Sasane S, Kramer A, Nair AG, Sartorius C, Hellgren Kotaleski J. 2019. Uncertainty quantification, propagation and characterization by Bayesian analysis combined with global sensitivity analysis applied to dynamical intracellular pathway models. Bioinformatics 35: 284-292. DOI: https:// doi.org/10.1093/bioinformatics/bty607, PMID: 30010712

Eriksson O. 2021. Aproximate Bayesian Computing (ABC) for parameter estimation in the AKAP79-PKA model. swh:1:rev:0fb83d341f568ac92340857be7886b3ccc3004b3. Software Heritage. https://archive. softwareheritage.org/swh:1:dir:eea01dca98bb87c64f66e04bd38112acc79848db;origin=https://github.com/ jdgas/AKAP79_PKA; visit=swh:1:snp:08f09916a5004fd8b7197d0a7709f5b47e6c4950; anchor=swh:1:rev:0fb8 3d341f568ac92340857be7886b3ccc3004b3

Gildart M, Kapiloff MS, Dodge-Kafka KL. 2020. Calcineurin-AKAP interactions: therapeutic targeting of a pleiotropic enzyme with a little help from its friends. The Journal of Physiology 598: 3029-3042. DOI: https:// doi.org/10.1113/JP276756, PMID: 30488951

Gold MG, Lygren B, Dokurno P, Hoshi N, McConnachie G, Taskén K, Carlson CR, Scott JD, Barford D. 2006. Molecular basis of AKAP specificity for PKA regulatory subunits. Molecular Cell 24: 383-395. DOI: https://doi. org/10.1016/j.molcel.2006.09.006, PMID: 17081989

Gold MG, Stengel F, Nygren PJ, Weisbrod CR, Bruce JE, Robinson CV, Barford D, Scott JD. 2011. Architecture and dynamics of an A-kinase anchoring protein 79 (AKAP79) signaling complex. PNAS 108: 6426-6431. DOI: https://doi.org/10.1073/pnas.1014400108, PMID: 21464287

Gold M. G. 2019. Swimming regulations for protein kinase A catalytic subunit. Biochemical Society Transactions 47: 1355-1366. DOI: https://doi.org/10.1042/BST20190230, PMID: 31671183

Goto S, Matsukado Y, Mihara Y, Inoue N, Miyamoto E. 1986. Calcineurin in human brain and its relation to extrapyramidal system. Immunohistochemical study on postmortem human brains. Acta Neuropathologica 72 150-156. DOl: https://doi.org/10.1007/BF00685977

Grigoriu S, Bond R, Cossio P, Chen JA, Ly N, Hummer G, Page R, Cyert MS, Peti W. 2013. The molecular mechanism of substrate engagement and immunosuppressant inhibition of calcineurin. PLOS Biology 11 : e1001492. DOI: https://doi.org/10.1371/journal.pbio.1001492, PMID: 23468591

Hao Y, England JP, Bellucci L, Paci E, Hodges HC, Taylor SS, Maillard RA. 2019. Activation of PKA via asymmetric allosteric coupling of structurally conserved cyclic nucleotide binding domains. Nature Communications 10: 3935. DOI: https://doi.org/10.1038/s41467-019-11930-2

Hinke SA, Navedo MF, Ulman A, Whiting JL, Nygren PJ, Tian G, Jimenez-Caliani AJ, Langeberg LK, Cirulli V, Tengholm A, Dell'Acqua ML, Santana LF, Scott JD. 2012. Anchored phosphatases modulate glucose homeostasis. The EMBO Journal 31: 3991-4004. DOI: https://doi.org/10.1038/emboj.2012.244, PMID: 22940692

Hogan PG. 2017. Calcium-NFAT transcriptional signalling in T cell activation and T cell exhaustion. Cell Calcium 63: 66-69. DOI: https://doi.org/10.1016/j.ceca.2017.01.014, PMID: 28153342

Hoshi N, Langeberg LK, Gould CM, Newton AC, Scott JD. 2010. Interaction with AKAP79 modifies the cellular pharmacology of PKC. Molecular Cell 37: 541-550. DOI: https://doi.org/10.1016/j.molcel.2010.01.014, PMID: 20188672 
Houslay MD, Baillie GS. 2005. Beta-arrestin-recruited phosphodiesterase-4 desensitizes the AKAP79/PKAmediated switching of beta2-adrenoceptor signalling to activation of ERK. Biochemical Society Transactions 33: 1333-1336. DOI: https://doi.org/10.1042/BST20051333, PMID: 16246112

Huang YY, Li XC, Kandel ER. 1994. cAMP contributes to mossy fiber LTP by initiating both a covalently mediated early phase and macromolecular synthesis-dependent late phase. Cell 79: 69-79. DOI: https://doi.org/10.1016/ 0092-8674(94)90401-4, PMID: 7923379

Ilouz R, Lev-Ram V, Bushong EA, Stiles TL, Friedmann-Morvinski D, Douglas C, Goldberg JL, Ellisman MH, Taylor SS. 2017. Isoform-specific subcellular localization and function of protein kinase A identified by mosaic imaging of mouse brain. eLife 6: e17681. DOI: https://doi.org/10.7554/eLife.17681, PMID: 28079521

Isensee J, Kaufholz M, Knape MJ, Hasenauer J, Hammerich H, Gonczarowska-Jorge H, Zahedi RP, Schwede F, Herberg FW, Hucho T. 2018. PKA-RIl subunit phosphorylation precedes activation by cAMP and regulates activity termination. The Journal of Cell Biology 217: 2167-2184. DOI: https://doi.org/10.1083/jcb.201708053, PMID: 29615473

Jurado S, Biou V, Malenka RC. 2010. A calcineurin/AKAP complex is required for NMDA receptor-dependent long-term depression. Nature Neuroscience 13: 1053-1055. DOI: https://doi.org/10.1038/nn.2613, PMID: 20694001

Kar P, Samanta K, Kramer H, Morris O, Bakowski D, Parekh AB. 2014. Dynamic assembly of a membrane signaling complex enables selective activation of NFAT by Orai1. Current Biology 24: 1361-1368. DOI: https:// doi.org/10.1016/j.cub.2014.04.046, PMID: 24909327

Kashishian A, Howard M, Loh C, Gallatin WM, Hoekstra MF, Lai Y. 1998. AKAP79 inhibits calcineurin through a site distinct from the immunophilin-binding region. The Journal of Biological Chemistry 273: 27412-27419. DOI: https://doi.org/10.1074/jbc.273.42.27412, PMID: 9765270

Keith DJ, Sanderson JL, Gibson ES, Woolfrey KM, Robertson HR, Olszewski K, Kang R, El-Husseini A, Dell'acqua ML. 2012. Palmitoylation of A-kinase anchoring protein 79/150 regulates dendritic endosomal targeting and synaptic plasticity mechanisms. The Journal of Neuroscience 32: 7119-7136. DOI: https://doi. org/10.1523/JNEUROSCI.0784-12.2012, PMID: 22623657

Kelker MS, Page R, Peti W. 2009. Crystal structures of protein phosphatase-1 bound to nodularin-R and tautomycin: a novel scaffold for structure-based drug design of serine/threonine phosphatase inhibitors. Journal of Molecular Biology 385: 11-21. DOI: https://doi.org/10.1016/j.jmb.2008.10.053, PMID: 18992256

Kinderman FS, Kim C, von Daake S, Ma Y, Pham BQ, Spraggon G, Xuong NH, Jennings PA, Taylor SS. 2006. A dynamic mechanism for AKAP binding to RIl isoforms of cAMP-dependent protein kinase. Molecular Cell 24: 397-408. DOI: https://doi.org/10.1016/j.molcel.2006.09.015, PMID: 17081990

Knape MJ, Ahuja LG, Bertinetti D, Burghardt NCG, Zimmermann B, Taylor SS, Herberg FW. 2015. Divalent Metal lons Mg2+ and $\mathrm{Ca} 2+$ Have Distinct Effects on Protein Kinase A Activity and Regulation. ACS Chemical Biology 10: 2303-2315. DOI: https://doi.org/10.1021/acschembio.5b00271, PMID: 26200257

Kwon HB, Sabatini BL. 2011. Glutamate induces de novo growth of functional spines in developing cortex. Nature 474: 100-104. DOI: https://doi.org/10.1038/nature09986, PMID: 21552280

Lee HK, Kameyama K, Huganir RL, Bear MF. 1998. NMDA induces long-term synaptic depression and dephosphorylation of the GluR1 subunit of AMPA receptors in hippocampus. Neuron 21: 1151-1162. DOI: https://doi.org/10.1016/s0896-6273(00)80632-7, PMID: 9856470

Li H, Pink MD, Murphy JG, Stein A, Dell'Acqua ML, Hogan PG. 2012. Balanced interactions of calcineurin with AKAP79 regulate Ca2+-calcineurin-NFAT signaling. Nature Structural \& Molecular Biology 19: 337-345. DOI: https://doi.org/10.1038/nsmb.2238, PMID: 22343722

Lu Y, Zhang M, Lim IA, Hall DD, Allen M, Medvedeva Y, McKnight GS, Usachev YM, Hell JW. 2008. AKAP150anchored PKA activity is important for LTD during its induction phase. The Journal of Physiology 586: 41554164. DOI: https://doi.org/10.1113/jphysiol.2008.151662, PMID: 18617570

Lu Y, Zha X, Kim EY, Schachtele S, Dailey ME, Hall DD, Strack S, Green SH, Hoffman DA, Hell JW. 2011. A kinase anchor protein 150 (AKAP150)-associated protein kinase A limits dendritic spine density. The Journal of Biological Chemistry 286: 26496-26506. DOI: https://doi.org/10.1074/jbc.M111.254912, PMID: 21652711

Mo GCH, Ross B, Hertel F, Manna P, Yang X, Greenwald E, Booth C, Plummer AM, Tenner B, Chen Z, Wang Y, Kennedy EJ, Cole PA, Fleming KG, Palmer A, Jimenez R, Xiao J, Dedecker P, Zhang J. 2017. Genetically encoded biosensors for visualizing live-cell biochemical activity at super-resolution. Nature Methods 14: 427-434. DOI: https://doi.org/10.1038/nmeth.4221, PMID: 28288122

Moore MJ, Adams JA, Taylor SS. 2003. Structural basis for peptide binding in protein kinase A. Role of glutamic acid 203 and tyrosine 204 in the peptide-positioning loop. The Journal of Biological Chemistry 278: 1061310618. DOI: https://doi.org/10.1074/jbc.M210807200, PMID: 12499371

Mulkey RM, Endo S, Shenolikar S, Malenka RC. 1994. volvement of a calcineurin/inhibitor-1 phosphatase cascade in hippocampal long-term depression. Nature 369: 486-488. DOl: https://doi.org/10.1038/369486a0, PMID: 7515479

Murphy JG, Sanderson JL, Gorski JA, Scott JD, Catterall WA, Sather WA, Dell'Acqua ML. 2014. AKAP-anchored PKA maintains neuronal L-type calcium channel activity and NFAT transcriptional signaling. Cell Reports 7: 1577-1588. DOI: https://doi.org/10.1016/j.celrep.2014.04.027, PMID: 24835999

Ni Q, Ganesan A, Aye-Han NN, Gao X, Allen MD, Levchenko A, Zhang J. 2011. Signaling diversity of PKA achieved via a Ca2+-cAMP-PKA oscillatory circuit. Nature Chemical Biology 7: 34-40. DOI: https://doi.org/10. 1038/nchembio.478, PMID: 21102470 
Nygren PJ, Mehta S, Schweppe DK, Langeberg LK, Whiting JL, Weisbrod CR, Bruce JE, Zhang J, Veesler D, Scott JD. 2017. trinsic disorder within AKAP79 fine-tunes anchored phosphatase activity toward substrates and drug sensitivity. eLife 6: e30872. DOI: https://doi.org/10.7554/eLife.30872, PMID: 28967377

Ogreid D, Døskeland SO. 1981. The kinetics of the interaction between cyclic AMP and the regulatory moiety of protein kinase II. Evidence for interaction between the binding sites for cyclic AMP. FEBS Letters 129: 282-286. DOI: https://doi.org/10.1016/0014-5793(81)80184-6, PMID: 6269881

Patel N, Stengel F, Aebersold R, Gold MG. 2017. Molecular basis of AKAP79 regulation by calmodulin. Nature

Communications 8: 1681. DOI: https://doi.org/10.1038/s41467-017-01715-w, PMID: 29162807

Perrino BA, Fong YL, Brickey DA, Saitoh Y, Ushio Y, Fukunaga K, Miyamoto E, Soderling TR. 1992.

Characterization of the phosphatase activity of a baculovirus-expressed calcineurin A isoform. The Journal of Biological Chemistry 267: 15965-15969 PMID: 1322410.,

Qi C, Sorrentino S, Medalia O, Korkhov VM. 2019. The structure of a membrane adenylyl cyclase bound to an activated stimulatory G protein. Science 364: 389-394. DOI: https://doi.org/10.1126/science.aav0778, PMID: 31023924

Qian H, Patriarchi T, Price JL, Matt L, Lee B, Nieves-Cintrón M, Buonarati OR, Chowdhury D, Nanou E, Nystoriak MA, Catterall WA, Poomvanicha M, Hofmann F, Navedo MF, Hell JW. 2017. Phosphorylation of Ser 1928 mediates the enhanced activity of the L-type Ca $2+$ channel Ca $v 1.2$ by the $\beta 2$-adrenergic receptor in neurons. Science Signaling 10: 463. DOI: https://doi.org/10.1126/scisignal.aaf9659

Rangel-Aldao R, Rosen OM. 1976. Dissociation and reassociation of the phosphorylated and nonphosphorylated forms of adenosine $3^{\prime}: 5^{\prime}$-monophosphate-dependent protein kinase from bovine cardiac muscle. The Journal of Biological Chemistry 251: 3375-3380 PMID: 179996.,

Redden JM, Dodge-Kafka KL. 2011. AKAP phosphatase complexes in the heart. Journal of Cardiovascular Pharmacology 58: 354-362. DOI: https://doi.org/10.1097/FJC.0b013e31821e5649, PMID: 21562429

Roach PJ, Depaoli-Roach AA, Hurley TD, Tagliabracci VS. 2012. Glycogen and its metabolism: some new developments and old themes. The Biochemical Journal 441: 763-787. DOI: https://doi.org/10.1042/ BJ20111416, PMID: 22248338

Rodriguez A, Ehlenberger DB, Dickstein DL, Hof PR, Wearne SL. 2008. Automated three-dimensional detection and shape classification of dendritic spines from fluorescence microscopy images. PLOS ONE 3: e1997. DOI: https://doi.org/10.1371/journal.pone.0001997, PMID: 18431482

Roy J, Cyert MS. 2009. Cracking the phosphatase code: docking interactions determine substrate specificity. Science Signaling 2: re9. DOI: https://doi.org/10.1126/scisignal.2100re9, PMID: 19996458

Sanderson JL, Gorski JA, Gibson ES, Lam P, Freund RK, Chick WS, Dell'Acqua ML. 2012. AKAP150-anchored calcineurin regulates synaptic plasticity by limiting synaptic incorporation of Ca2+-permeable AMPA receptors. The Journal of Neuroscience 32: 15036-15052. DOI: https://doi.org/10.1523/JNEUROSCI.3326-12.2012, PMID: 23100425

Sanderson JL, Gorski JA, Dell'Acqua ML. 2016. NMDA Receptor-Dependent LTD Requires Transient Synaptic Incorporation of $\mathrm{Ca}^{2+}$-Permeable AMPARs Mediated by AKAP150-Anchored PKA and Calcineurin. Neuron 89: 1000-1015. DOI: https://doi.org/10.1016/j.neuron.2016.01.043, PMID: 26938443

Schmitt JP, Kamisago M, Asahi M, Li GH, Ahmad F, Mende U, Kranias EG, MacLennan DH, Seidman JG, Seidman CE. 2003. Dilated cardiomyopathy and heart failure caused by a mutation in phospholamban. Science 299: 1410-1413. DOI: https://doi.org/10.1126/science.1081578, PMID: 12610310

Smith FD, Esseltine JL, Nygren PJ, Veesler D, Byrne DP, Vonderach M, Strashnov I, Eyers CE, Eyers PA, Langeberg LK, Scott JD. 2017. Local protein kinase A action proceeds through intact holoenzymes. Science 356: 1288-1293. DOI: https://doi.org/10.1126/science.aaj1669, PMID: 28642438

Stemmer PM, Klee CB. 1994. Dual calcium ion regulation of calcineurin by calmodulin and calcineurin B. Biochemistry 33: 6859-6866. DOI: https://doi.org/10.1021/bi00188a015, PMID: 8204620

Taylor SS, Meharena HS, Kornev AP. 2019. Evolution of a dynamic molecular switch. IUBMB Life 71: 672-684. DOI: https://doi.org/10.1002/iub.2059, PMID: 31059206

Tillo SE, Xiong WH, Takahashi M, Miao S, Andrade AL, Fortin DA, Yang G, Qin M, Smoody BF, Stork PJS, Zhong H. 2017. Liberated PKA Catalytic Subunits Associate with the Membrane via Myristoylation to Preferentially Phosphorylate Membrane Substrates. Cell Reports 19: 617-629. DOI: https://doi.org/10.1016/j celrep.2017.03.070, PMID: 28423323

Tulsian NK, Krishnamurthy S, Anand GS. 2017. Channeling of cAMP in PDE-PKA Complexes Promotes Signal Adaptation. Biophysical Journal 112: 2552-2566. DOI: https://doi.org/10.1016/j.bpj.2017.04.045, PMID: 28636912

Tunquist BJ, Hoshi N, Guire ES, Zhang F, Mullendorff K, Langeberg LK, Raber J, Scott JD. 2008. Loss of AKAP150 perturbs distinct neuronal processes in mice. PNAS 105: 12557-12562. DOI: https://doi.org/10. 1073/pnas.0805922105, PMID: 18711127

Walker-Gray R, Stengel F, Gold MG. 2017. Mechanisms for restraining cAMP-dependent protein kinase revealed by subunit quantitation and cross-linking approaches. PNAS 114: 10414-10419. DOI: https://doi.org/10.1073/ pnas.1701782114, PMID: 28893983

Weisenhaus M, Allen ML, Yang L, Lu Y, Nichols CB, Su T, Hell JW, McKnight GS. 2010. Mutations in AKAP5 disrupt dendritic signaling complexes and lead to electrophysiological and behavioral phenotypes in mice. PLOS ONE 5: e10325. DOI: https://doi.org/10.1371/journal.pone.0010325, PMID: 20428246

Wild AR, Sinnen BL, Dittmer PJ, Kennedy MJ, Sather WA, Dell'Acqua ML. 2019. Synapse-to-Nucleus Communication through NFAT Is Mediated by L-type $\mathrm{Ca}^{2+}$ Channel $\mathrm{Ca}^{2+}$ Spike Propagation to the Soma. Cell Reports 26: 3537-3550. DOI: https://doi.org/10.1016/j.celrep.2019.03.005, PMID: 30917310 
Woolfrey KM, O'Leary H, Goodell DJ, Robertson HR, Horne EA, Coultrap SJ, Dell'Acqua ML, Bayer KU. 2018. CaMKII regulates the depalmitoylation and synaptic removal of the scaffold protein AKAP79/150 to mediate structural long-term depression. The Journal of Biological Chemistry 293: 1551-1567. DOI: https://doi.org/10. 1074/jbc.M117.813808, PMID: 29196604

Xiong WH, Qin M, Zhong H. 2021. Myristoylation alone is sufficient for PKA catalytic subunits to associate with the plasma membrane to regulate neuronal functions. PNAS 118: e2021658118. DOI: https://doi.org/10.1073/ pnas.2021658118

Zhang X, Li L, McNaughton PA. 2008. Proinflammatory mediators modulate the heat-activated ion channel TRPV1 via the scaffolding protein AKAP79/150. Neuron 59: 450-461. DOI: https://doi.org/10.1016/j.neuron. 2008.05.015, PMID: 18701070

Zhang J, Shapiro MS. 2012. Activity-dependent transcriptional regulation of M-Type (Kv7) K(+) channels by AKAP79/150-mediated NFAT actions. Neuron 76: 1133-1146. DOI: https://doi.org/10.1016/j.neuron.2012.10. 019, PMID: 23259949

Zhang Ping, Smith-Nguyen EV, Keshwani MM, Deal MS, Kornev AP, Taylor SS. 2012. Structure and allostery of the PKA RII $\beta$ tetrameric holoenzyme. Science 335: 712-716. DOI: https://doi.org/10.1126/science.1213979, PMID: 22323819

Zhang P, Knape MJ, Ahuja LG, Keshwani MM, King CC, Sastri M, Herberg FW, Taylor SS. 2015. Single Turnover Autophosphorylation Cycle of the PKA RIIß Holoenzyme. PLOS Biology 13: e1002192. DOI: https://doi.org/10. 1371/journal.pbio.1002192, PMID: 26158466

Zhang J, Shapiro MS. 2016. Mechanisms and dynamics of AKAP79/150-orchestrated multi-protein signalling complexes in brain and peripheral nerve. The Journal of Physiology 594: 31-37. DOI: https://doi.org/10.1113/ jphysiol.2014.287698, PMID: 25653013

Zhang X, Pathak T, Yoast R, Emrich S, Xin P, Nwokonko RM, Johnson M, Wu S, Delierneux C, Gueguinou M, Hempel N, Putney JW, Gill DL, Trebak M. 2019. A calcium/cAMP signaling loop at the ORAl1 mouth drives channel inactivation to shape NFAT induction. Nature Communications 10: 1971. DOI: https://doi.org/10.1038/ s41467-019-09593-0

Zhang JZ, Lu TW, Stolerman LM, Tenner B, Yang JR, Zhang JF, Falcke M, Rangamani P, Taylor SS, Mehta S, Zhang J. 2020. Phase Separation of a PKA Regulatory Subunit Controls cAMP Compartmentation and Oncogenic Signaling. Cell 182: 1531-1544. DOI: https://doi.org/10.1016/j.cell.2020.07.043, PMID: 32846158

Zhou Q, Homma KJ, Poo M. 2004. Shrinkage of dendritic spines associated with long-term depression of hippocampal synapses. Neuron 44: 749-757. DOI: https://doi.org/10.1016/j.neuron.2004.11.011, PMID: 15572107 